\title{
DOE/ER/M566i-1
}

\section{Kentucky DOE-EPSCoR Program}

\author{
Final Report
}

DOE Award Number: DE- $\$$ C02-91ER75661

September 30, 1991-December 31, 2002

Submitted by

John M. Stencel, Director - Kentucky DOE EPSCoR Program

Melissa P. Ochsenbein, Assistant Director - Kentucky DOE EPSCoR Program

www.epscor.org

(859) 257-0250

for the

KY DOE EPSCoR Subcommittee

on behalf of the

Kentucky EPSCoR Committee

P.O. Box 1049

Lexington, KY 40588

(859) 233-3502

April 14, 2003

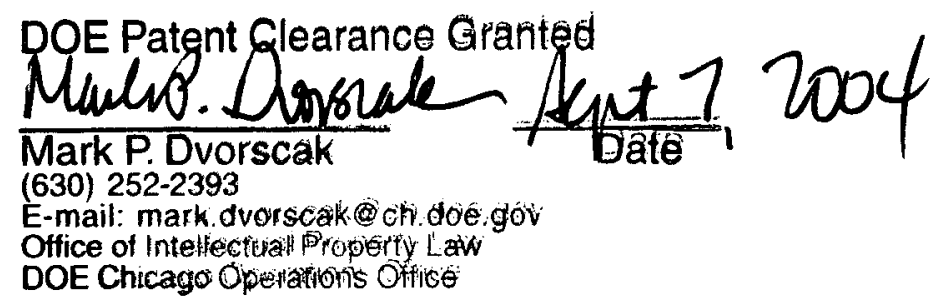




\section{DISCLAMER}

This report was prepared as an account of work sponsored by an agency of the United States Government. Neither the United States Government nor any agency thereof, nor any of their employees, makes any warranty, express or implied, or assumes any legal liability or responsibility for the accuracy, completeness, or usefulness of any information, apparatus, product, or process disclosed, or represents that its use would not infringe privately owned rights. Reference herein to any specific commercial product, process, or service by trade name, trademark, manufacturer, or otherwise does not necessarily constitute or imply its endorsement, recommendation, or favoring by the United States Government or any agency thereof. The views and opinions of authors expressed herein do not necessarily state or reflect those of the United States Government or any agency thereof. 


\section{DISCLAIMER}

Portions of this document may be illegible in electronic image products. Images are produced from the best available original document. 


\section{Kentucky DOE EPSCoR Program}

\section{EXECUTIVE SUMMARY}

The KY DOE EPSCoR Program is dedicated to establishing excellence in education and research and to promoting stable and progressive economic development in Kentucky. This dedication is defined in the following report showing a comprehensive and focused effort that built on the initiatives and successes starting with the first year of funding within a DOE EPSCoR Implementation Award in 1994. The Program included efforts to impact positively the pipeline of science and engineering students and to establish research, education and business infrastructure, sustainable beyond DOE EPSCOR funding.

The KY DOE EPSCoR Program supported four research clusters. These clusters, including Fossil Energy, Environmental Sciences, High Energy and Nuclear Physics, and Materials Research, originated from four universities - Murray State University, University of Kentucky, University of Louisville and Western Kentucky University - and included research interactions with other Kentucky universities. Overall, cooperative research was performed at six Kentucky universities, seven DOE National Laboratories and at eight industries within the US.

The Program also supported human resource development projects. Seven universities within Kentucky, including Eastern Kentucky University, Murray State University, Northern Kentucky University, Pikeville College, University of Kentucky, University of Louisville and Western Kentucky University, cooperatively participated in these educational components. The projects improved educational opportunities throughout the Commonwealth, including high school math and science students, preservice science teachers currently attending college as undergraduates, high school teachers who were teaching science and math, science and engineering graduate students, faculty at small four year Appalachian and historically black colleges and universities, and university research faculty and staff. These activities were coordinated with the Kentucky Education Reform Act, the Appalachian Rural Systemic Initiative, and other EPSCoR programs funded by industry, the Commonwealth of Kentucky and the US government.

Funding for the Kentucky DOE EPSCoR Program during the period of 1991-2002 within the Implementation Grant starting in 1994 and the initial Planning Grant is presented below. This funding period included no-cost extensions through December 31, 2002.

\begin{tabular}{lrrrr} 
YEAR & USDOE, $\$$ & Kentucky. \$ & Total, \$ \\
\cline { 2 - 2 } 1991-1993 & & & \\
$\quad$ Planning Grant) & 100,000 & & 100,000 \\
$1994-1996$ & $1,246,274$ & 850,000 & $2,096,274$ \\
1997 & 925,000 & 550,000 & $1,475,000$ \\
1998 & 750,000 & 510,000 & $1,260,000$ \\
1999 & 750,000 & 510,000 & $1,260,000$ \\
2000 & 750,000 & 510,000 & $1,260,000$ \\
$2000-2002$ (no cost) & $\frac{0}{4,521,274}$ & $2,930,000$ & $\frac{0}{7,351,274}$ \\
TOTAL & & &
\end{tabular}




\title{
Kentucky DOE EPSCoR Program Report
}

\author{
Table of Contents
}

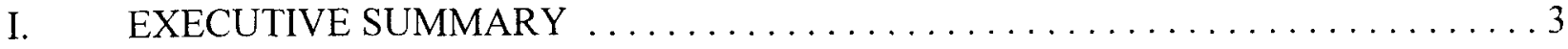

II ORGANIZATION AND ADMINISTRATION $\ldots \ldots \ldots \ldots \ldots \ldots \ldots \ldots \ldots$

III HUMAN RESOURCE DEVELOPMENT PROJECTS $\ldots \ldots \ldots \ldots \ldots \ldots \ldots \ldots$

a. Energy Workshops for High School Chemistry and Physics Teachers (Phase I) and Establishing Science Alliances for High School Physical Science Teachers (Phase II) - Western Kentucky University . . . . . . . . . . . . . . 5

b. INSPIRE (Increasing Student Preparedness and Interest in the Requisites for Engineering) - University of Louisville . . . . . . . . . . . . . 8

c. Center for Applied Energy Research High School Internship Program -

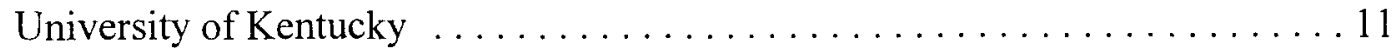

d. Chemistry for Pre-service Elementary Teachers - Northern Kentucky University . . . . . . . . . . . . . . . . . . . . . . . 13

e. Students Weatherization/Audit Training (SWAT Jr.) - Commonwealth of

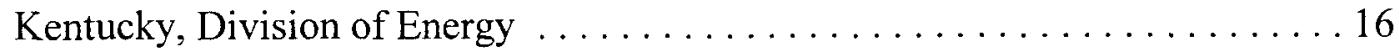

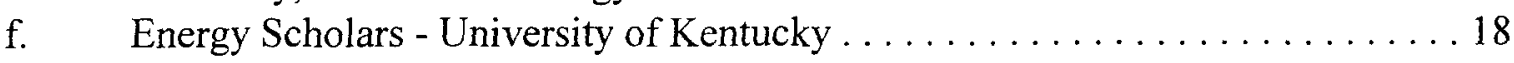

g. Nuclear and Radiochemistry in Chemistry Curriculum - University of Kentucky . ............................. 19

h. Science Works - Physics Proficiency in Elementary and Middle Grades -

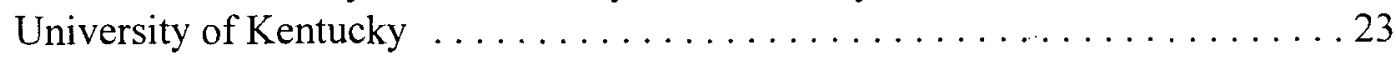

i. Entrepreneurship and Enterprise Development Institute - Kentucky Science \&

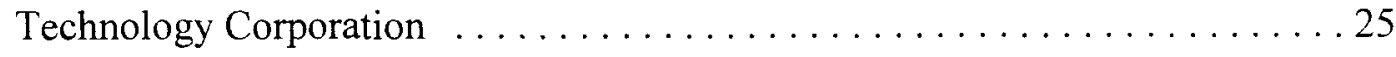

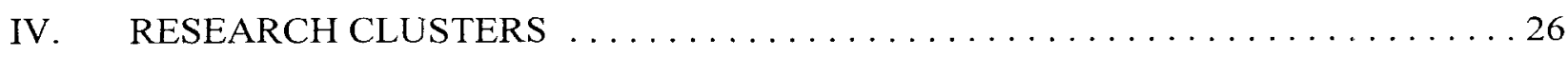

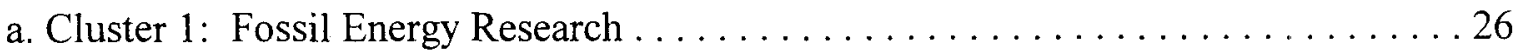

1. Project 1: On-Line Elemental Coal Characterization - Western Kentucky University . . . . . . . . . . . . . . . 26

2. Project 2: Investigation of the Behavior of Potentially Hazardous Trace Elements in Kentucky Coals and Combustion Products University of Kentucky $\ldots \ldots \ldots \ldots \ldots \ldots \ldots \ldots \ldots \ldots \ldots \ldots \ldots \ldots$

3. Project 3: Supporting Technologies for Effective Use of On-line Analyzers in Control of Coal Quality - University of Kentucky . . . . . 37

b. Cluster 2: Environmental Science Research

1. Project 1: Transport, Accumulation and Utilization of Organic Carbon in Large Reservoir Systems - Murray State University . . 
2. $\quad$ Project 2: Reservoir-Watershed Linkages: The Effects of Water Level Management on Hydrology and Water Quality in Hydro-Electric

Reservoirs - Murray State University . . . . . . . . . . . . . . . . 48

c. Cluster 3: High Energy and Nuclear Physics Research ................ . 49

1. Project 1: High Energy Physics - University of Kentucky . . . . . . . 49

2. Project 2: Experimental Nuclear Physics at CEBAF - University of Kentucky ...............................61

d. Cluster 4: Materials Research ...........................67 67

1. Project 1: Synthesis and Applications of Sol-Gel Yittria Stabilized Zirconia - University of Kentucky . . . . . . . . . . . . . . . . . 67

2. Project 2: Optimization of Heat Treatment of Aluminum-SiliconMagnesium Alloys - Western Kentucky University ............ 73

3. Project 3: Development of MEMS for DOE Applications - University of Louisville . . . . . . . . . . . . . . . . . . . . . . . . . . 74

4. Project 4: Enhancement of Low-Field Magnetostriction In Thin, Multilayer Films for Device and Sensor Applications - University of Kentucky 
The universities participating in the Kentucky DOE EPSCoR Program also provided significant cost share to ensure that the required 1-to-1 overall match was provided for attracting the DOE funding. Their cost share was $\$ 5,355,181$.

The universities used this funding to build expertise and national recognition. As a consequence, faculty and staff supported by Kentucky DOE EPSCoR generated an additional $\$ 25,109,328$ in federal, state and industrial support during the period of 1994-to-2001. All of this funding was outside of EPSCoR programs. In other words, Kentucky researchers leveraged federal funding by a factor of 5.6; they leveraged Commonwealth of Kentucky funding by a factor of 8.6, and leveraged the federal plus state funding by a factor of 3.4. This leveraging attests to the vibrant ideas and scientific creativity of Kentucky researchers.

\section{ORGANIZATION AND ADMINISTRATION}

The KY DOE EPSCoR Program is one component of the Statewide EPSCoR Program. The Statewide Program is administered by the Kentucky EPSCoR Committee. It is comprised of business, government and education leaders who are dedicated to improving education and research competitiveness in Kentucky. The umbrella organization of the EPSCoR Committee is the Kentucky Science and Technology Corporation (KSTC), a not-for-profit organization that formulates and implements systemic initiatives throughout Kentucky.

The KY DOE ESPCoR Program reports through the Director of Statewide EPSCoR Program, Rick Kurzynske, to the Kentucky EPSCoR Committee. The Chair of the Kentucky EPSCoR Committee is Dr. Wimberly Royster.

The initiation, implementation and coordination of the KY DOE EPSCoR Program was performed by the KY DOE EPSCOR Subcommittee. It solicited and developed statewide collaborations, agreements and projects, promoted information transfer, helped to establish liassons between participating universities, coordinated research and human resources development efforts, submitted reports to the DOE and the Committee, and assessed, in conjunction with the Committee, impacts and improvements brought about by the DOE EPSCoR Program.

The KY DOE EPSCoR Program was statewide in scope and involved eight universities and colleges within Kentucky, local and state governments, local and state educational personnel, industries and not-for-profit businesses. An identification and distribution of the participant Kentucky universities are presented in Figure 1. Each of the participant universities obligated financial and human resources to help attain the goals of the Program. Industries nationwide and the national DOE laboratories were also part of the cooperative efforts.

The Statewide EPSCoR Committee and all of its Subcommittees are independent of the state government and university administrations, thereby providing an autonomy in decisions and a flexibility in directions. This type of structure implies that interactions between EPSCoR administrators, its program components and with all participant organizations have to be nutured if EPSCoR is to impact the State's research and education infrastructure. As a consequence, the Statewide EPSCoR Committee and the KY DOE EPSCoR Subcommittee consist of key administrators and faculty who are dedicated to the EPSCoR goals. It also has prominent idustrial and government members who have donated their time and talent to promote EPSCoR 


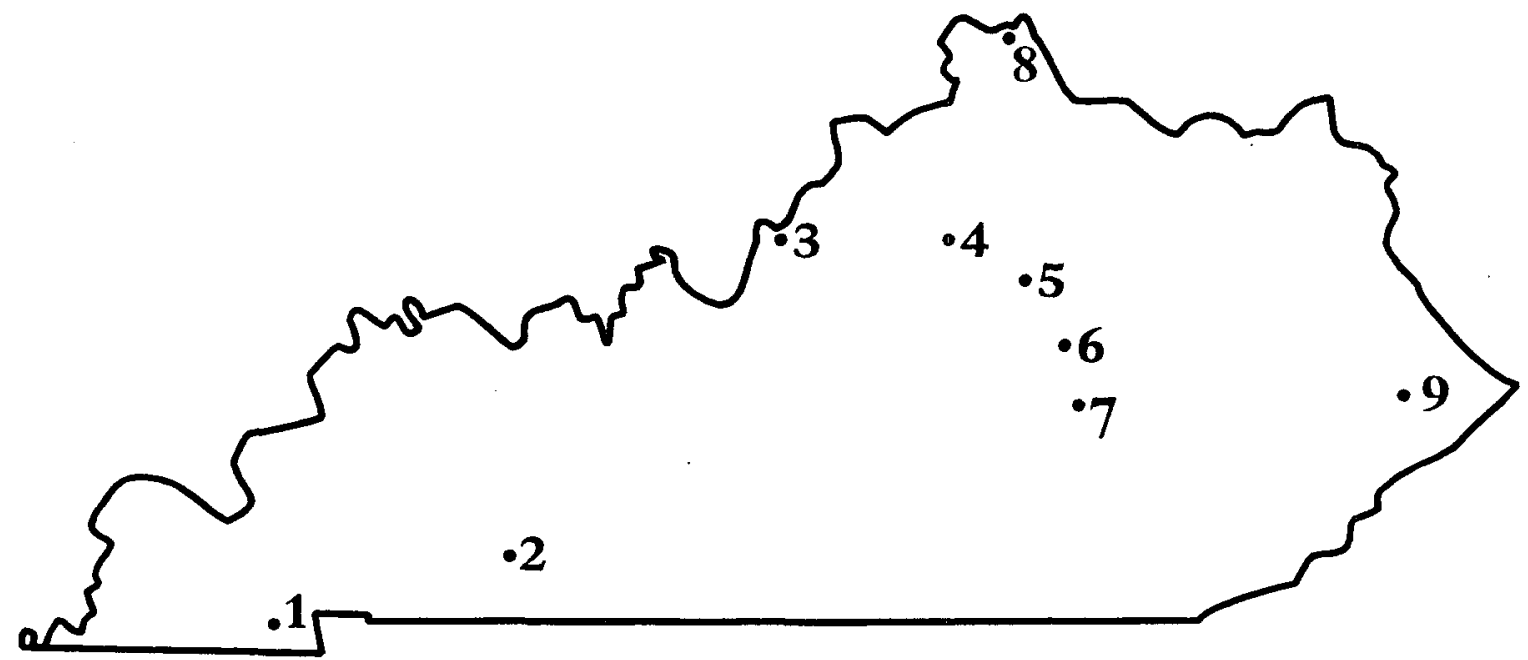

Figure 1. Participant Universities in the KY DOE EPSCoR Program.

Legend: 1) Murray State University (MSU), Murray; 2) Western Kentucky University (WKU), Bowling Green; 3) University of Louisville (UL), Louisville; 4) Kentucky State University (KSU), Frankfort; 5) University of Kentucky (UK), Lexington; 6) Eastern Kentucky University (EKU), Richmond; 7) Northern Kentucky University (NKU), Highland Heights; 8) Pikeville College (PC), Pikeville.

This type of structure has been and continues to be successful for Kentucky. Besides integrating and coordinating the EPSCoR efforts within the DOE, NSF, NASA, DOD and NIH programs, a focus of the Statewide EPSCoR Committee is to interface and to develop participation with state and local governments.

\section{HUMAN RESOURCE DEVELOPMENT PROJECTS}

III.a. Energy Workshops for High School Chemistry and Physics Teachers (Phase I) and Establishing Science Alliances for High School Physical Science Teachers (Phase II)

PRINCIPAL INVESTIGATOR: Lowell W. Shank, Western Kentucky University. Department of Chemistry, Western Kentucky University, One Big Red Way, Bowling Green, KY 42101; tel (270) 745-4986; fax (270) 745-5361; email: lowell.shank@wku.edu.

\section{SUMMARY}

Phase I: Five regional summer workshops, each lasting one week and involving up to 25 participants, were held at Western Kentucky University, University of Louisville, Eastern Kentucky University, Murray State University and Pikeville College during the summer of 1995 and repeated during the summer of 1996. The purposes of these workshops were to: (1) promote 
a better understanding of what every consumer should know about energy and energy prognosis to high school chemistry and physics teachers; (2) disseminate energy information through demonstrations and video tapes, providing copies where available; (3) show teachers how to perform energy experiments in high school laboratories using equipment available at the high schools; (4) promote the use of student-centered activities and decision-making exercises; (5) focus on new state and federal education initiatives in which valued outcomes, objectives, and hands-on pedagogy are focal directions; (6) provide access to industrial chemists and physicists active in the field of energy; and (7) encourage teachers to share information about their demonstrations and/or laboratory activities through local alliances and state science teachers' meetings.

Phase II: This second phase of the project developed and expanded regional Science Alliances to facilitate interaction among physical science teachers throughout Kentucky. Energyrelated resource materials were demonstrated and then given to participants for them to use in their schools. Make-and-take sessions were also conducted. Local Coordinators were employed for five Energy Workshop during the summers of 1995 and 1996. They, along with university/college representatives, served on steering committees having the responsibility of recruiting participants and making final arrangements for the Workshops. Five additional sites in Northern Kentucky, Ashland, Hopkinsville, Somerset and Henderson were included as locations for the Workshops to provide better regional access throughout the Commonwealth. High school teachers also assumed more responsibility for planning and conducting Alliance meetings.

\section{FUNDING}

DOE: $\$ 115,201$

Commonwealth of Kentucky: $\$ 89,449$

Total: $\$ 204,650$

\section{ACCOMPLISHMENTS}

The number of participants in the five workshops held during the summer of 1995 was 56. This number grew to in 1996 to 70.

The number of Alliance meeting held each year and the number of participants were: 1996: 4 meetings in three months, 30 participants

1997: 18 meetings, 278 participants

1998: 16 meetings, 161 participants

1999: 12 meetings, 200 participants

2000: 7 meetings, including a week-long Flinn Scientific Foundation Summer Chemistry Workshop at WKU, 107 participants

2001: 3 meetings in nine months, 60 participants.

The total number of meetings in six years was 60 , i.e. an average of 10 -per-year; the total number of participants was 836 .

To conduct these meetings, Dr. Lowell Shank traveled to locations throughout Kentucky. It was convenient to deliver hands-on training and educational experiences to students either 
before or after the Alliances meetings. Hence, he conducted Chemical Magic Shows and delivered slide presentations on Energy and Careers in Chemistry. These events included:

- 1996,7 locations in three months to 1,220 students

- $\quad$ 1997, 18 locations, 3,760 students;

- $\quad 1998,33$ locations, 7,340 students;

- $\quad 1999,25$ locations, 5,790 students;

- $\quad 2000,31$ locations, 5,625 students;

- $\quad 2001,19$ locations in nine months, 3,950 students.

The total number of locations visited during six years was 133 , i.e. an average of 27 -peryear; the total number of students reached was 27,735 .

A $\$ 60,000$ follow-on grant was received as a result of the infrastructure and networking developed through the DOE EPSCoR funding. Its title was "Increase the Chemical Science Knowledge of Teachers and to Provide Support for Classroom Activities" by Larry Byrd, Lester Pesterfield and Lowell Shank, Western Kentucky University. It was co-funded by Western and the Council of Postgraduate Education (CPE), Commonwealth of Kentucky.

\section{PUBLICATIONS AND PRESENTATIONS}

"Energy Workshop for High School Teachers - Part I; How it Was Organized for Summer 1995, and Looking Ahead to 1996" 81 st Kentucky Academy of Science, Western Kentucky University, Bowling Green, KY, November, 1995.

"Energy Workshop for High School Teachers - Part II: Content of Hands-On Workshops in 1995 and 1996" 81st Kentucky Academy oaf Science, Western Kentucky University, Bowling Green, KY, November, 1995.

"Resources for Teaching About Renewable Energy" Annual Math/Science Conclave of PRISMUG, Louisville, KY, March 1996.

"Energy Workshops for High School Physical Science Teachers" 14th Biennial Conference on Chemical Education, Clemson University, Clemson, SC, August, 1996.

"Resources for Teaching About Renewable Energy" 14th Biennial Conference on Chemical Education, Clemson University, Clemson, SC, August, 1996.

"Establishing High School/College Science Teachers Alliances" 82nd Kentucky Academy of Science, Kentucky State University, Frankfort, KY, November, 1996.

"The Mystery of the Great Science Alliance Meetings Unraveled" Kentucky Science Teachers Association, Lexington, KY, November, 1997. 
"How to Include Energy Concepts in Classes at all Grade Levels" 83rd Kentucky Academy of Science, Morehead State University, Morehead, KY, November, 1997.

"Establishing High School/College Science Teachers Alliances" 15th Biennial Conference on Chemical Education, Waterloo, Ontario, CAN, August, 1998.

"How to Start and Conduct Alliances in Your Area" 84th Kentucky Academy of Science, Jefferson County Community College, Louisville, KY, November, 1998.

"Let's Have a Teacher Alliance Meeting" 14th ChemEd 99, Fairfield University, Fairfield, CT, August, 1999.

"Chemistry Demonstrations" Kentucky Science Teachers Association, Lexington, KY, November, 1999.

"Scope of 'Flinn Scientific Workshop on Demonstrations' held at Western Kentucky University" 16th Biennial Conference on Chemical Education, University of Michigan, Ann Arbor, MI, August, 2000.

"Demonstrations with a Touch of Magic" 15th ChemEd 2001, York University, Toronto, Ontario, CAN, August, 2001.

\section{AWARDS}

Western Kentucky University Unit Productivity Award to the Chemistry Department, 1998 and 2001. All departments at WKU may apply for this award by submitting a list of significant accomplishments during each academic year to the Dean of unit in which a department is located. Rational for the award included that a) the DOE EPSCoR external grant had been received; b) it enhanced the responsiveness to constituents of the University through extensive outreach; c) it enabled faculty to give 25 presentations during 2001 to schools and libraries throughout the Commonwealth of Kentucky; d) it enabled the Chemistry Department to sponsor a week-long Flinn Chemical Workshop for 39 high school science teachers; e) it provided the necessary support for a faculty member at WKU to coordinate Science Alliance meetings for high school science teachers throughout Kentucky; and f) it provided the impetus and support for submission of the proposal to the Council on Postsecondary Education for continued funding of the Science Alliance initiative.

III.b INSPIRE (Increasing Student Preparedness and Interest in the Requisites for Engineering)

PRINCIPAL INVESTIGATOR: Brenda G. Hart, Academic Services Office, Speed Scientific School, University of Louisville, Louisville, KY 40292, tel: (502) 852-0440; fax: (502) 8526268; email: brenda@louisville.edu 
CO-PRINCIPAL INVESTIGATORS: Dr. J.P. Mohsen, Department of Civil Engineering, Speed Scientific School, University of Louisville, Louisville, KY 40292, tel (502) 852-4596; fax (502) 852-8851; email: jpmohs01@gwise.louisville.edu

Veronica Hinton-Hudson, Computer Information Systems, College of Business and Public Administration, University of Louisville, Louisville, KY 40292, tel (502) 852-0127; fax (502) 852-6027; email: hinton-hudson@hotmail.com.

Dr. Gail DePuy, Department of Industrial Engineering, Speed Scientific School, University of Louisville, Louisville, KY 40292; tel (502) 852-0115; fax (502) 852-5633; email:

gwdepu01@gwise.louisville.edu.

Dr. John Usher, Department of Industrial Engineering, Speed Scientific School, University of Louisville, Louisville, KY 40292, tel (502) 852-0085; fax (502) 852-5633; email:

jsushe01@gwise.louisville.edu.

\section{SUMMARY}

The INSPIRE acronym stands for Increasing Student Preparedness and Interest in the Requisites for Engineering. It was and continues to be a four-week summer enrichment program designed to provide ethnic minority high school students with the opportunity to participate in studies related to basic engineering skills in a college environment. INSPIRE targets ethnic minority students (African American, Hispanic, Native Americans) and females because they are under-represented in the engineering fields. Each summer, approximately 30 tenth or eleventh grade students from the greater Louisville-Jefferson County area participate in this program. The students are recommended by their high school math and/or science teachers and have demonstrated abilities in math and science.

INSPIRE is a program designed to empower participants to think more about acquiring a degree of proficiency in a technological area through participation in laboratory-oriented studies. The program consists of three hours of classroom training Mondays through Thursdays for four weeks each summer. The students utilize the facilities and equipment of the University of Louisville's Speed Scientific School from 9:30AM to 12:30PM. They apply newly-acquired technical skills in solving problems with practical applications.

Participants in INSPIRE learn more about themselves by participating in a "True Colors" session. This program is an entertaining way in which students learn to better understand and value themselves. The students learn to better respect each individual and to embrace their similarities and differences.

In another part of the program, the students are given a brief introduction to the computer algebra system MAPLE. Challenging problems from algebra, probability and two-and-three dimensional geometry are introduced and students work in groups doing hands-on activities.

Students are also given an introduction to Computer-aided-design (CADD) which include automated graphic systems for creating and displaying multi-view and 3D drawings. The students are also introduced to a production and manufacturing "just-in-time"system within 
industrial engineering. Through simulations, the INSPIRE students experience the advantages and disadvantages of control schemes for assembly line production. The students work in teams which physically simulate the production of an item. Students also address energy-related topics and environmental concerns.

Following a general introduction to mixture design and field control of Portland cement concrete, the students participate in hands-on concrete mixing session in the civil engineering lab. The students are also provided with a brief introduction to the disciplines of chemical and mechanical engineering.

The INSPIRE students also are taken on weekly field trips to such locations as the Louisville Water Company, General Electric Appliances, the Metropolitan Sewer District, North American Stainless and Louisville Gas and Electric. Such excursions allowed the students to see engineers and technicians at work on actual projects.

\section{PROJECT FUNDING}

DOE: $\$ 52,429$

Commonwealth of Kentucky: $\$ 49,467$

Total: $\$ 101,896$

\section{ACCOMPLISHMENTS}

Since 1994, 187 minority students have participated in the INSPIRE program. Some accomplishments include:

- $\quad 123$ of the INSPIRE participants were female (65.7\%) and $64(34.2 \%)$ were male

- The ethnic breakdown of the students included 111 African American (59.3\%), 58

Caucasian (31\%), 14 Asian (7.4\%), and 4 Hispanic (2\%);

- Tracking of students who participated in INSPIRE was accomplished in 1998. INSPIRE began in 1981; the DOE EPSCoR funding provided support for its expansion and for a previously unavailable assessment. This assessment showed:

a. 529 students had participated in INSPIRE between 1981 to 1998 (an average of nearly 30 student per year);

b. Of these, 156 had earned college degrees from the public universities in Kentucky;

c. 61 of these degrees were in engineering, 5 in math and 6 in biology;

d. 122 of the 156 had graduated from the University of Louisville.

In other words, nearly $30 \%$ of the high school students having the INSPIRE experience graduated from college. And, almost $12 \%$ of the high school students chose either engineering or science for their major!

\section{PUBLICATIONS AND PRESENTATIONS}

Hart, B. and Mohsen, J.P. "A Calculus Retention Program for Students at Risk in Engineering", 
Proceedings, 1995 ASEE Annual Conference, June, 1995.

Hart, B. : "Clustering Women and Students of Color in an Orientation Class for Engineering Students", Proceedings, WEPAN/NAMEPA Joint National Conference, March, 1997.

Hart, B. and Hinton-Hudson, V.: "A Discipline-Specific Early Intervention Program for Recruitment of Minorities into Engineering - the Pilot Study Results", Proceedings, NAMEPA annual conference, December, 1999.

Hart, B. and Hinton-Hudson, V.: "CAMP IE: A Discipline-Specific Model for the Recruitment of Minorities," Proceedings, ASEE Annual Conference, June, 2000.

AWARDS (to Brenda Hart)

Recipient of Faculty Appreciation Award from the University of Louisville, Office of Minority Services, 1996 and 1998.

Recipient of Bethune Service Award from National Council of Negro Women, 1996.

Recipient of Speed Scientific School's Alumni Scholar for Service Award, 1996.

Recipient of Trustees Award from the University of Louisville Board of Trustees, 1997. This award, presented annually to a UofL employee, recognizes faculty who have made "significant contributions" to the life of undergraduate students. It was established by UofL's Board of Trustees and comes with a monetary award of $\$ 5,000$.

Initiated into Phi Kappa Pi honorary society, 1999.

III.c. University of Kentucky Center for Applied Energy Research (CAER) High School Internship Program

PRINCIPAL INVESTIGATOR: Marybeth McAlister, Center for Applied Energy Research, University of Kentucky, 2540 Research Park Dr., Lexington, KY 40511, tel (859) 257-0224; fax (859) 257-0302; email mcalister@caer.uky.edu.

CO-PRINCIPAL INVESTIGATOR: Dr. James Hower, Center for Applied Energy Research, University of Kentucky, 2540 Research Park Dr., Lexington, KY 40511, tel (859) 257-0261; fax (859) 257-0302; email hower@caer.uky.edu.

\section{SUMMARY}

The Center for Applied Energy Research (CAER) established its summer high school internship program in 1993. Its short-term objectives were to expose rural students to research 
and development, to gain hands-on experience with energy research, and to interact with professionals in energy engineering and scientific fields. The long-term objectives were to invest in the state's future, to increase the number of college-going Kentuckians in science and engineering, and to recruit science students for the university. The CAER funding for the internship program was supplemented by DOE EPSCoR starting in 1997. The program continues as of this report.

The program involved an annual, two-week experiential effort for rural high school students take part in and offer input to energy related research. It provided one-on-one mentoring. It introduced these students to university campus life by their lodging in university dormitories and interacting with students from various parts of the state.

Individual student projects were in the fields of catalysis, fine-coal cleaning, fly ash beneficiation, coal petrography, carbon materials, and analytical and environmental studies. The educational experience also included field trips to mines and coal-fired utilities.

Students were selected by applications which included personal statements of interest in science and engineering and high school coursework and grade transcripts. All students were at least 16 years old. They were required to have a teacher's recommendation, and to have completed at least one year of chemistry. Before final selection, the principal investigators traveled to the high schools to interview the student applicants.

\section{PROJECT FUNDING}

DOE: $\$ 107,900$

Commonwealth of Kentucky: $\$ 63,960$

Total: $\$ 171,860$

\section{ACCOMPLISHMENTS}

- 31 high school students participated in the project during the DOE EPSCoR funding. Since 1993, 47 students have participated.

- $\quad$ Three of the students were subsequently hired at the CAER to work in energy research during summers when they were at the University of Kentucky.

- Of the 47 high school students, 25 of those going to college chose science and/or engineering majors.

The CAER is continuing the internships for students living nearby the CAER and plans to have up to six more high school students during the summer of 2003.

\section{PUBLICATIONS AND PRESENTATIONS}

(Summer interns as co-authors are denoted by italics in the following)

Hower, J.C., Trimble, A.S., Eble, C.F., Palmer, C., and Kolker, A., 1999, Characterization of Fly Ash from Low-sulfur and High-sulfur Coal Sources: Partitioning of carbon and trace elements 
with particle size: Energy Sources, v. 21, p. 511-525.

Hower, J.C., Finkelman, R.B., Rathbone, R.F., and Goodman, J., 2000, Intra- and Inter-unit Variation in Fly Ash Petrography and Mercury Adsorption: Examples from a Western Kentucky Power Station: Energy \& Fuels, v. 14, p. 212-216.

Hower, J.C., Thomas, G.A., and Palmer, J., 1999, Impact of the Conversion to Low $\mathrm{NO}_{x}$ Combustion on Ash Characteristics in a Utility Boiler Burning Western US Coal: Fuel Processing Technology, v. 61, p. 175-195.

McAlister, M.; Hower, J.C. "Experiential education in energy resources and technology: High school intern program at the University of Kentucky," 112th Geological Society of America Annual Meeting, Nov. 9-18, Reno, NV, Abstracts with Programs, 32, A268, 2000.

\section{III.d. Chemistry for Pre-service Elementary Teachers}

PRINCIPAL INVESTIGATOR: Dr. Vinay Kumar; Department of Chemistry, Northern Kentucky University, Highland Heights, KY 41099; tel (859) 572-5408; fax (859) 572-5162; email kumar@nku.edu.

CO-PRINCIPAL INVESTIGATOR: Dr. Vernon Hicks, Department of Chemistry, Northern Kentucky University, Highland Heights, Ky 41099; tel (859) 572-5406; fax (859) 572-5162; email: hicks@nku.edu.

\section{SUMMARY}

An integrated lecture and lab course, Discovering Chemistry with Lab (CHE 105), was established through this Kentucky DOE EPSCoR Program funding and has become a permanent course at Northern Kentucky University (NKU). Even though CHE 105 is designed primarily for the education majors, it is open to all liberal arts and business students as a general studies course. Each semester up to thirty-six students are enrolled in the course. A web site (www.nku.edu/ chemistry/che105) for this course was established in 1998. It is used by the students to access the syllabus, lecture $\&$ lab schedules and the various assignments. It also provides links to educational resources on the web.

One of the goals of this course was to improve chemical education of pre-service elementary and middle school teachers. It promotes reasoning and problem-solving skills by utilizing computer-based technologies and hands-on, discovery/guided-inquiry, and cooperative learning approaches.

CHE 105 covers basic principles of chemistry and their application in daily life. Multimedia tools (e.g. CD-ROM, HyperStudio-based units and internet) are used to present selected topics in the lecture course. In addition, the students use internet and the CD-ROM accompanying the textbook to do assignments and a group presentation.

In CHE 105 lab three computer-interfacing and two computer-simulation experiments 
that were first introduced in 1995 are being continued. For the first five years these experiments were carried out with Power Mac and PC desktop computers. In spring of 2001 the desktop computers were replaced with Mac and PC lap tops with wireless networking. The funds for purchasing these lap tops were provided by the Office of Information and Technology at NKU.

In the spring of 2002, the Computer-Based Lab (CBL) data collection units were replaced with new Vernier Lab Pro data collection units. The Lab Pros accept over thirty inexpensive sensors and can be interfaced both with Texas Instrument (TI) graphing calculators and PC and Mac computers.

A HyperStudio-based multimedia unit on Molecular Modeling has also been completed. This unit covers ways of representing molecules, the construction of molecular models using classroom model kits, and the vibrational, rotational, and translational motions of molecules in space. Currently, students do an in-class project involving the use of classroom model kits. Eight copies of the Spartan molecular modeling software have been purchased to augment this in-class project with computer-based construction of molecules.

\section{FUNDING}

DOE: $\$ 101,733$

Commonwealth of Kentucky: $\$ 89,412$

Total: $\$ 191,145$

\section{ACCOMPLISHMENTS}

The accomplishments of this project include:

- $\quad$ The establishment of a permanent, new course that focuses on educating educators.

- Three publications in national education journals (see listing below).

- Presentations describing the established course were given at thirteen state, regional, national and international conferences (see listing below).

- $\quad$ During 1997-2000, DOE EPSCoR funded stipends for two undergraduate students and two high school teachers who worked as summer interns. Both students became coauthors on the presentations that were given at two professional conferences. Their names are italized in the list of presentations below.

- $\quad$ Four surveys were administered after establishing the course to provide an evaluation and assessment of instructional strategies that were introduced in the lecture and lab courses.

- Pre-course and post-course surveys about the laboratory experiences were given to the students. The results of these surveys showed a positive gain as a consequence of students taking the course relative to other course offering which did not have hands-on and technology-based experiences. This gain was, notably, in enhanced confidence toward teaching science to elementary and middle grades students and utilizing new technology to do this.

- A computer survey was designed and used to evaluate student experiences in the use of computers for laboratory demonstrations and to measure student attitudes toward using computers in teaching science. The results from this survey revealed strongly favorable 
responses toward the introduction and use of computers in the classroom to gather and analyze data, as well as to present science concepts. Students also indicated that computer based laboratory units for collecting data were relatively easy to use.

- The Technology Survey was designed to get feedback from students on integration of technology in the classroom. Results from this survey indicate that the students find the use of multimedia lessons and CD-ROM in the classroom to be useful in learning the abstract topics in chemistry. These results indicate clearly that the project has been successful in meeting its goals. Also, the students like the course website and find it to be very useful for accessing course syllabus, schedule and the assignments.

- Another survey was mailed to the student-teachers in the field after they had taken the course at NKU. Its purpose was to see how the 'graduates' of CHE 105 were utilizing the technology skills learned in this course. Since the number of students who have graduated from CHE 105 is small right now (80), the results of this survey will be analyzed only after a reasonable number of responses have been received.

- The following funding and funding initiatives are a consequence of the opportunities and infrastructure created by the DOE EPSCoR project.

-Incorporating Technology-Based Data Acquisition into the Middle Grade Curriculum" workshop; Center for Integrative Natural Science and Math (CINSAM), NKU; $\$ 28,000$; Jan. 1, 2001- Dec. 31, 2001.

-Flinn Summer Chemistry Workshop", Flinn/Cinsam; \$12,900; Jan. 1, 2001 - September $1,2001$.

-Incorporating Technology-Based Data Acquisition into the Middle Grade Curriculum" workshop; Center for Integrative Natural Science and Math (CINSAM), NKU; $\$ 27,985$; Jan. 1, 2000- Dec. 31, 2000

-Re-establishing Science Alliances for Northern Ky Middle and High School teachers"; CINSAM; \$20,000; ; Jan. 1, 2000- Dec. 31, 2000.

-Modern Computational Software" purchase; CINSAM; $\$ 5239 ;$; Jan. 1, 2000- Dec. 31 , 2000 .

\section{PUBLICATIONS AND PRESENTATIONS}

"Collaboration: The Chemistry Between Colleagues"; Allen H. Seed, Vinay Kumar, Julia Bedell and Vernon Hicks; Proceedings of SITE (Society for Information Technology \&Teacher Education); 11 th International Conference, Feb. 8-12, 2000; San Diego, CA. "Technology: Catalyst for Enhancing Chemical Education for Pre-service Teachers"; Vinay Kumar, Julia Y. Bedell and Allen H. Seed; J.Chem. Educ. 76, 713-717, May 1999.

"Computers and Videodisc Technologies: Catalysts for Improving Chemistry Education for PreTeachers"; Kumar, V.; Bedell, J.; Effective Teaching. 10, Spring, 1995.

"Presenting Polymers with Hyperstudio"; Vinay Kumar and Lee McCoy; 32nd ACS Central Regional Meeting, May 16-19, 2000, Covington, KY. 
"Collaboration: The Chemistry Between Colleagues"; Allen H. Seed, Vinay Kumar, Julia Bedell and Vernon Hicks; 11 th International SITE (Society for Information Technology \&Teacher Education) Conference, Feb. 8-12, 2000; San Diego, CA.

"Chemistry for Pre-Service Teachers Episode VI: Graduation"; Vinay Kumar, W. Vernon Hicks, Julia Y. Bedell, Allen H.Seed; 6th KY EPSCoR Conference, May 15, 2000, Frankfort, $\mathrm{KY}$.

"Introduction of CBL Experiments in the Chemistry Course for Pre-Service Teachers", Vernon Hicks and Vinay Kumar; 5th KY EPSCoR Conference, May 11, 1999, Somerset, KY.

"Integrating Computer Technology in a New Chemistry Course", Vinay Kumar, Laura Trovillo, and W. Vernon Hicks; 1999 Kentucky Education Technology Conference; March 4-6, 1999, Louisville, KY.

"Use of Computer Technology in a Chemistry Course for Pre-service Teachers", Vinay Kumar and Julia Y. Bedell, 15th Biennial Conference on Chemical Education, Waterloo, Ontario, Canada; August 9-13, 1998.

"Progress \& Assessment of Chemistry Curricular Reform" V. Kumar, 4th KY EPSCoR Conference, Louisville, KY, May 11, 1998.

"Technology: Catalyst for Enhancing Chemical Education for Pre-service Teachers", A. Seed, J. Bedell and V. Kumar; 8th International SITE (Society for Information Technology \&Teacher Education) Conference; Orlando, FL., April 2, 1997.

"Chemistry Education for Pre-ServiceTeachers: Progress and Assessment"; J. Bedell and V. Kumar, 3rd KY EPSCoR Conference, Lexington, KY, May 8, 1997.

"Technology in a Chemistry Classroom for Pre-Service Teachers", Vinay Kumar and Julia Y. Bedell, 2nd annual KY EPSCoR Conference, Louisville, KY; May 6, 1996.

"Technology in a Chemistry Classroom for Pre-Service Teachers", Vinay Kumar and Julia Y. Bedell, 1996 Kentucky Education Technology Conference; Louisville, KY; March 3, 1996. "Integrating Technology into a Chemistry Course for Pre-Service Teachers", Vinay Kumar and Julia Y. Bedell, 4th Annual PRISM Math/Science Conclave, Louisville, KY; March 2, 1996.

"Computer Technology: Catalysi for Enhancing Chemistry Education for Pre-Teachers", Vinay Kumar and Julia Y. Bedell, 1st Annual KY EPSCoR Conference; Lexington, KY, May 8, 1995.

III.e. Students Weatherization/Audit Training (SWAT Jr.)

PRINCIPAL INVESTIGATOR: John Stapleton, Division of Energy, Natural Resources \& 
Environmental Protection Cabinet, Commonwealth of Kentucky, 663 Teton Trail, Frankfort, KY 40601, tel (502) 564-7192, fax (502) 564-7484, email stapleton_j@mail.nr.state.ky.us

\section{SUMMARY}

Under the SWAT Jr. program, high school and vocational school applicants were solicited, interviewed and then became participants for and in an energy education project funded by the U.S. Department of Energy and the Kentucky Natural Resources and Environmental Protection Cabinet's Division of Energy (KDOE). The KDOE conducted an energy conservation and education program for school facilities and their students, faculty and staff. Any public, private or nonprofit high school or vocational school was eligible to participate.

Controlling energy costs provides both an economic resource to schools and a learning opportunity for students. The program trained faculty and students to become "energyconscious" and to study energy as it relates to everyday usage in their school facilities. SWAT Jr. provided a real-world, hands-on exercise that benefitted both the school and the students involved.

During the school year, students analyzed energy usage in the school, set up an energyconsumption record-keeping system, conducted energy audits of school facilities, determined payback of energy-efficiency measures, studied operation and maintenance procedures, and presented a report with recommendations to the principal and school board. A designated faculty member at the school was responsible for overseeing and coordinating the project; both the coordinator and two students (sophomores, juniors or seniors) were trained during a three-day training session at the Kentucky Leadership Center in Jabez, Kentucky.

The training included a mixture of seminars, field trips, and hands-on experience. Guest speakers, including facilities management experts and energy education professionals, described energy conservation and wastage as related to facilities operations. The student and teacher participants conducted a practice audit during a walk-through of a school. The goal of this training was to provide practical experience and materials that the designated coordinators and students would use at their school during the school year.

During the school year, the KDOE provided technical assistance to each school's SWAT Jr. project team. Additionally, the participating schools were eligible to receive a $\$ 150$ "minigrant" that was used for the purchase of materials, supplies, or services for the project.

For becoming a participating institution in a SWAT Jr. project, each school agreed to participate by:

(A) securing school board and administration approval of the school's participation;

(B) sending one teacher or staff member and two students to a three-day training session;

(C) forming a "SWAT Team" at each school that consisted of 18 to 30 students for conducting an energy audit;

(D) conducting SWAT Jr. activities during the school year;

(E) attending a progress meeting sponsored by the KDOE;

(F) presenting a energy audit report to school officials and the local school board or other administrative body. 


\section{FUNDING}

DOE: $\$ 43,945$

Commonwealth of Kentucky: \$43,945

Total: $\$ 87,890$

\section{ACCOMPLISHMENTS}

Over 25 schools participated in the SWAT, Jr. program during its funding. With an average of 25 students per school each year who were involved in facility energy audits, more than 625 students were educated using hands-on experiences by the program. Additionally, school administrators from Illinois and North Carolina attended the training courses with the vision to establish similar programs in their states. The Kentucky program was deactivated after the principal investigator retired from $\mathrm{KDOE}$.

\section{III.f. Energy Scholars}

PRINCIPAL INVESTIGATOR: Dr. Marcus McEllistrem, Department of Physics and Astronomy, University of Kentucky, Lexington, KY 40506; tel (606) 257-3403; fax (606) 257 1577; emailmarcue@serverl.pa.uky.edu

\section{SUMMARY}

The Energy Scholars Project was begun in October 1994. It provided summer research support for faculty and students from undergraduate colleges and universities within Kentucky to work with research institutions like the University of Kentucky or the University of Louisville.

After soliciting proposals, two projects were selected during the Fall 1995. These were funded in May 1996; summer stipends of the students and one month summer salaries of the faculty were paid.

One project included faculty and students from Western Kentucky University who worked at the University of Louisville, Department of Biology. Their project was entitled Factors Controlling the Zooplankton Community Structure in the Ohio River. The other project involved faculty and students from Berea College who worked at the University of Kentucky, Department of Physics. Their project was entitled New Techniques for Quantum Gauge Theories.

\section{FUNDING}

DOE: $\$ 13,972$

Commonwealth of Kentucky: $\$ 22,500$

Total: $\$ 36,472$ 


\section{ACCOMPLISHMENTS}

The Energy Scholars project tested the concept that faculty and students from undergraduate colleges and universities who became more involved in research at $\mathrm{PhD}$ granting universities would improve student education opportunities and faculty talents at the undergraduate schools. Although this project was very small and lasted only two years, it cemented some long-term cooperation between the $\mathrm{PhD}$-granting and undergraduate institutions. The two faculty members at Berea College and Western Kentucky University became coprincipal investigators on research proposals funded in biological and high energy physics studies at the University of Kentucky. Furthermore, a pipeline of talented students for graduate studies was established for the University of Kentucky and University of Louisville.

The Energy Scholars project became a precursor to an ongoing program funded by the Kentucky EPSCoR Program using Commonwealth of Kentucky funding. Called the Pipeline Program, faculty and students at non-doctoral granting institutions connect with researchers at either the University of Kentucky or the University of Louisville. The faculty/student team commits to research at one of these institutions during two summers, and maintains contact throughout the year. Students involved in this program and matriculating to graduate school must apply to either UK or UofL, and the faculty member must submit a research proposal for a federal grant jointly with the host faculty at the end of the two years.

\section{III.g. Nuclear and Radiochemistry in Chemistry Curriculum}

PRINCIPAL INVESTIGATOR: J. David Robertson, Department of Chemistry, University of Kentucky, Lexington, KY 40506-0055, tel (859) 257-7070, fax (859) 323-1069, email jdrobson@pop.uky.edu

CO-PRINCIPAL INVESTIGATOR: Elizabeth W. Kleppinger, Research Associate, Department of Chemistry, University of Kentucky, Lexington, KY 40506-0055, tel (859) 986-3253, fax (859) 323-1069, email bklep00@pop.uky.edu

\section{SUMMARY}

The NRICh Curriculum (Nuclear and Radiochemistry in Chemistry Curriculum) Project involved a five-step process: 1) development of curriculum materials designed to incorporate nuclear and radiochemistry in the traditional undergraduate chemistry curriculum;2) presentation of these materials at four-day summer workshops to college-level faculty from HBCU and Appalachian-located universities and college; 3 ) testing of these materials by the workshop participants in their classrooms for one school year; 4) two-day follow-up workshops to obtain feedback from the participants; 5) and then revision of the original curriculum materials. Participants were provided with the revised material, as well as with continuing support in the form of email and telephone communication, instrumentation loans, and new curriculum materials as they were developed.

The first four-day workshop was held during August of 1995; at this time, curriculum 
materials designed to be used during the first two years of college-level chemistry were presented to 18 participants. Half of these were from HBCU's and half from CACU's (central Appalachian colleges and universities).

During the 1995/96 academic year, the participants from the first workshop tested the following NRICh modules in their classrooms:

First-Year Chemistry: The Periodic Table; Radon; Nuclear Power;

Organic Chemistry: Medical Imaging; Radiolysis; Chemical Reactions and Radiochemistry

They also used general materials provided in the curriculum notebook covering the topics of Natural Sources of Radiation, Radiation Safety and Public Perception, and Types of

Radioactive Decay. In addition, a module titled "Intersections," detailing various areas of traditional chemistry in which there are compelling parallels or enlightening illustrations in nuclear and radiochemistry, was available in the curriculum notebooks.

Support was provided to the workshop participants during this school year in the following ways:

1. Questions were answered as they arose.

2. Current events relating to the curriculum, contributed by both participants and by the principal investigators, were shared with participants.

3. A glossary and index to the curriculum materials were prepared.

4. Corrections and revisions to the modules were begun.

5. In August of 1996, a two-day follow-up workshop, attended by eleven of the original participants was held.

At this time, reports were given by each of the teachers who had previously attended the course, and suggestions for changes, corrections, and additions to the curriculum notebooks were discussed along with collaborative brainstorming for additional ideas. Also at this time, plans were begun for obtaining instrumentation that could be made available on loan to the participants.

Following are selected results from the first follow-up workshops. Collectively, the 11 participants attending the follow-up workshop had:

a) used materials on all of the topics in the curriculum notebook, including effects \& risks of radiation, the periodic table, radon, nuclear power, medical imaging, food irradiation, synthesis of labeled compounds, thermodynamics and kinetics, data and exercises

b) incorporated a wide range of activities in their classrooms and labs, such as attitude/perceptions surveys, brief additions to existing topics, single-period treatments of nuclear topics, multiple-period special topics in nuclear science, demonstrations, handson lab experiments, and student assignments.

The second four-day workshop was held during August of 1997; at this time, the revised curriculum materials, designed to be used during the first two years of college-level chemistry, were presented to 16 participants.

First-Year Chemistry: The Periodic Table; Radon; Nuclear Power 
Organic Chemistry: Medical Imaging; Radiolysis; Chemical Reactions and

Radiochemistry; Natural Sources of Radiation; Radiation Safety and Public Perception;

Types of Radioactive Decay; Intersections (between traditional and nuclear chemistry)

Units covering quantum mechanics (for use in physical chemistry) and counting statistics

(for use in analytical chemistry) were added to the original units. The 16 workshop

participants began using these materials in their classrooms at the start of the $1997 / 98$

school year.

Support was provided to the workshop participants during their academic year in the

following ways: 1. Questions were answered as they arose; 2 . Additional modules for analytical and physical chemistry were prepared; 3 . Ten Geiger-Möller lab stations were made available on loan basis to participants in either the first or second four-day workshop.

Then, in the summer of 1998/99 year, a second follow-up workshop was held in which ten of the 16 participants came back to Lexington to share their experiences and their recommendations for curriculum additions.

\section{PARTICIPATING INSTITUTIONS}

The participants in this Nuclear and Radiochemistry in the Chemistry Curriculum Workshop series came from the following colleges and universities.

\begin{tabular}{|c|c|}
\hline Southeast Community College & Hampton University \\
\hline Cumberland, KY & Hampton, VA \\
\hline Kentucky State University & Tuskegee University \\
\hline Frankfort, KY & Montgomery, AL \\
\hline Spelman College & Union College \\
\hline Atlanta, GA & Barbourville, $\mathrm{KY}$ \\
\hline Union University & Fort Valley State University \\
\hline Jackson, TN & Fort Valley, GA \\
\hline Coastal Carolina University & University of Tennessee \\
\hline Myrtle Beach, SC & Knoxville, TN \\
\hline Claflin College & Transylvania University \\
\hline Orangeburg, SC & Lexington, $\mathrm{KY}$ \\
\hline Morehead State University & Bellarmine College \\
\hline Morehead, KY & Louisville, KY \\
\hline Fisk University & Livingstone College \\
\hline Nashville, TN & Salisbury, NC \\
\hline
\end{tabular}


Fayetteville State University

Fayetteville, NC

Lees College

Jackson, KY

Mississippi Valley State University

Greenwood, MS

Kentucky Wesleyan College

Owensboro, KY

Savannah State College

Savannah, GA

Alabama State University

Montgomery, AL

Shepherd College

Shepherdstown, WV

Winston-Salem State University

Winston-Salem, NC

Queens College

Charlotte, NC

FUNDING

DOE: $\$ 181,916$

Commonwealth of Kentucky: $\$ 48,886$

Total: $\$ 230,802$
Tuskegee University

Auburn, AL

Lane College

Jackson, TN

Salem-Teikyo University

Salem, WV

Centre College

Lexington, $\mathrm{KY}$

Milligan College

Elizabethton, TN

Alice Lloyd College

Pippa Passes, KY

Christian Brothers University

Holly Springs, MS

Jackson State University

Brandon, MS

\section{ACCOMPLISHMENTS}

Dr. Robertson worked on establishing other funding and submitted proposals to the National Science Foundation that would provide additional support for developing a NRICh Curriculum. Although his proposals were rated in the upper $25 \%$, they were not funded. Then he was offered and accepted a Professorship in Missouri that also included him being in charge of a nuclear radiochemistry laboratory. As a consequence, the NRICh concept was no longer pursued in Kentucky.

PRESENTATIONS/PUBLICATIONS 
"Reincorporating Nuclear Chemistry as Topic and Tool in the Undergraduate Chemistry and High School Science Curricula." by E. W. Kleppinger and J. D. Robertson, 211 th American Chemical Society National Meeting, New Orleans, April 1996. [Invited talk for symposium in honor of W. D. Ehmann, recipient of the 1996 ACS Award for Nuclear Chemistry.

"Pushing the Wrong Buttons: Nuclear Science as Portrayed in the Popular Media" by E. W. Kleppinger and J. D. Robertson. Fall 1997 American Chemical Society National Meeting in Las Vegas.

"Nuclear Science as Topic and Tool in the Undergraduate Chemistry and High School Science Curricula" by E. W. Kleppinger and J. D. Robertson, Fall 1997 American Chemical Society Meeting in Las Vegas.

"Incorporating Nuclear Chemistry in the Traditional Undergraduate Chemistry Curriculum" (Invited) August 1998, American Chemical Society, Boston, MA.

When Electrons Aren't Enough: Applications of Radioanalytical Chemistry" (Invited) November 1998, Department of Chemistry, Texas A\&M University, College Station, TX.

E.W. Kleppinger and J.D. Robertson, Incorporating Nuclear Chemistry as an Education Tool in the Undergraduate Chemistry Curriculum: A Description of the Curriculum Project, $J$. Radioanal. Nucl. Chem. 219, 247-250 (1997).

III.h. Science Works - Physics Proficiency in Elementary and Middle Grades

PRINCIPAL INVESTIGATOR: Joseph P. Straley, Department of Physics and Astronomy, University of Kentucky, Lexington, KY 40506, tel (859) 257-3197, fax (859) 323-2846, email straley@pa.uky.edu

SUMMARY

This project was funded for one year. It had a statewide human resource development scope, providing 125 elementary and middle school teachers with content training and understanding in physics content topics and instructional strategies. These strategies followed education recommendations of the National Science Education Standards and Kentucky's Core Content for Science Assessment. The project provided abundant inquiry-based physics classroom equipment and instructional materials, and training in their implementation. It expanded on an initiative within the University of Kentucky's Department of Physics and Astronomy since 1994, founded on the belief that it is crucial to engage upper elementary and middle school students and teachers in high quality, challenging, age appropriate, and active science study.

FUNDING 
DOE: $\$ 32,625$

Commonwealth of Kentucky: $\$ 10,875$

Total: $\$ 43,490$

\section{ACCOMPLISHMENTS}

- $\quad$ rovided content understanding and classroom materials to $115 \mathrm{KY}$ elementary and middle school teachers. Topics included Light; Temperature \& Heat; Energy and Forces; Electric Circuits; Magnetism; and Simple Machines. Increased teacher confidence and enthusiasm in physics.

- Changed classroom practices of participating teachers so that inquiry based physics is now a regular part of science classrooms, and advanced science process skills are regularly applied.

- Formed our most highly successful single-district collaboration with Pike County in eastern KY, with EPSCoR funds providing the impetus for their in-depth Middle School Science Academy. Beyond the grant sponsored 12 hours of training, Pike has enabled us to provide an additional 60 hours of physics instruction to the same group of teachers over a 2 year period. Such intensive work is unusual in a district-wide forum.

- Established project continuation beyond EPSCoR funding, with plans under way for 2001-02 school year professional development in Pike County. (others also anticipated).

- Partnered with Kentucky Department of Education Regions 5 and 8 Science Consultants to offer professional development within their regions.

- Achieved greater degree of time commitment than expected from participants. The proposal specified 6 to 12 hours instruction for each participant. In actuality:

- $31 \%$ received 24 or more hours of training, with half of these currently on track for a total of 72 hours;

$-23 \%$ received from 6 to 9 hours;

$-38 \%$ received 12 hours;

- only $8 \%$ fell below the minimum of 6 hours proposed.

- $\quad$ Provided larger classroom equipment kits than proposed due to greater interest and commitments from participating district.

\section{PRESENTATIONS \& PUBLICATIONS}

The principal investigator was involved in teacher training in Kentucky during the period of October 1999-to-September 2000, and during the period of October 1999-to-February 2001. In addition, a presentation was given, within the Eisenhower Professional Development Session, Higher Education as a Partner in School's Systemic Change Process; US Dept. of Education $7^{\text {th }}$ Annual National Conference, Improving America's Schools (October 2 2000) Louisville KY.

ACCOMPLISHMENTS 
A proposal was funded by the Kentucky Council on Postsecondary Education, Eisenhower Program, entitled Physics in Eastern Kentucky Classrooms. Its funding level was $\$ 57,948$ with a period of performance from January 2000-June 2001.

This human resource development program continues within the Department of Physics and Astronomy, albeit at a lower level of funding. Its content has been adapted for local school presentations and teacher education.

\section{III.i. Entrepreneurship and Enterprise Development Institute}

PRINCIPAL INVESTIGATOR: Kris Kimel, President, Kentucky Science \& Technology Corporation, PO Box 1049, Lexington, KY 40588, tel (859) 233-3502, fax (859) 259-0986, email kkimel@kstc.com

CO-PRINCIPAL INVESTIGATOR: Joanne Lang, Vice President, Kentucky Science \& Technology Corporation, PO Box 1049, Lexington, KY 40588, tel (859) 233-3502, fax (859) 259-0986, email jlang@kstc.com

\section{SUMMARY}

This project was an integrated effort to focus on the economic development needs of Kentucky. The Institute began in 1996-97, and four annual events were held, each of which were two days in duration. It directly impacted the long term goals of increasing the economic impact of science and technology developments in Kentucky and the knowledge of Kentucky university faculty and staff in developing businesses using their ideas and research outcomes. When begun, this initiative realized that while Kentucky was primarily dependent on agriculture and coal production, and these sectors will continue to offer an important base of employment, the reliance on a non-technological basis is neither expansive nor oriented toward progressive development of its citizens and economy. The Institute was the first of its kind in Kentucky, and considered extremely important for helping to promote commercialization of products, instruments and ideas and helping to instill an entrepreneurial spirit within faculty in Kentucky's colleges and universities.

The Institute was run as a workshop in which attendees were given high energy learning experiences, targeting the "how to's" of starting an innovation-driven company, product or service. A team of experienced entrepreneurs and professionals led the Institute. The faculty provided critical information, key start-up strategies, business tools and a network of people to help create a product or company.

At each two-day Institute attendees learned about:

- how to value and convert ideas, research and technological expertise into commercially viable products and business ventures;

- the knowledge and skills required to successfully start a company or transfer an idea to the marketplace;

- how to tap available capital resources and financing strategies;

- the elements of a successful business plan; and 
- how to protect your intellectual property and discuss other proprietary protection issues.

FUNDING

DOE: $\$ 65,809$

Commonwealth of Kentucky: $\$ 83,188$

Total: $\$ 148,997$

\section{ACCOMPLISHMENTS}

Four Annual Kentucky Commercialization \& Entrepreneurship Institutes were held. Typically held in April of each year, three were at Shaker Village of Pleasant Hill in Harrodsburg, KY and one was at Midway College, Midway, Kentucky. Over 70 attendees from throughout Kentucky attended.

The project collaborated with a number of organizations and companies in the design and implementation of the Institutes. They included the University of Kentucky, University of Louisville, DataBeam Corporation, Council on Postsecondary Education, ArchSoft, California State University Institute, Kentucky Technology Service, Inc., National Institute of Standards and Technology, King \& Schlicki Patent Attorneys, Coopers \& Lybrand; Kentucky Technology Inc., Kentucky State University and Maine Science and Technology Foundation.

As an outgrowth of the Institute, a workshop for students was also initiated. Called Gorilla Tactics for the Student Entrepreneur Workshop, it was built as a unique, high-octane experience and workshop for Kentucky college and university students interested in creating innovative new enterprises. Participants learned about start-up tactics, capitalizing ventures, business strategy and concept valuation. They also became part of "The Gorilla Group", a webbased entity that provided an opportunity for college and university students to exchange ideas and information, network with experienced entrepreneurs, and learn key knowledge and skills related to entrepreneurship.

\section{RESEARCH CLUSTERS}

\section{IV.a. Fossil Energy Research}

There were three fossil energy research projects within Kentucky DOE EPSCoR during the funding period of 1994-to-2002. These are summarized in the following narrative.

\section{Project 1: On-Line Elemental Coal Characterization}

PRINCIPAL INVESTIGATOR: George Vourvopoulos, Department of Physics, Western Kentucky University, Bowling Green, KY 42101, tel (502) 781-3859, fax (502) 781-1104, email Vour@wku.edu 
CO-PRINCIPAL INVESTIGATORS: Douglas Humphrey, Western Kentucky University, Bowling Green, KY 42101; tel (502) 781-3859, fax (502) 781-1104, email dhump@wku.edu

Phil Womble, and Fred Schultz, Waste \& Remedial Actions Division, Oak Ridge National Laboratory, Oak Ridge, TN 37830, tel (423) 576-6870, emailsfj@ornl.gov

Sandor Sudar, Visiting Professor (from Debrecen University, Hungary); Linus Dep, Research Associate; Mike Belbot, Research Associate; and Jennifer Ball, Jon Paschal, Keith Persons, Gary Spichiger, undergraduate students

\section{SUMMARY}

This project addressed the development of on-line instrumentation to measure properties of coal and coal byproducts that are used and produced by fossil energy industries. Importantly, the control of sulfur emissions to the environment from coal fired power plants is paramount. Since any economical reduction of the sulfur content of coal used by utilities is through blending of various coals, the development of a neutron-based elemental coal analyzer was proposed. Using pulsed neutrons produced from a neutron generator, an on-line analyzer was conceptualized and built to measure the amount of $\mathrm{H}, \mathrm{N}, \mathrm{C}, \mathrm{O}, \mathrm{Al}, \mathrm{Si}, \mathrm{Cl}, \mathrm{Ca}, \mathrm{S}, \mathrm{Fe}$, etc. contained in coal. The identification of each element was through characteristic gamma-ray emission after excitation using neutrons. Through these measurements, bulk properties such as calorific value, moisture, density, volatile matter, etc. was also targeted using algorithms such as:

$$
\text { Calorific value }(\mathrm{BTU} / \mathrm{lb})=\mathrm{a}(\% \mathrm{C})+\mathrm{b}(\% \mathrm{H})+\mathrm{c}(\% \mathrm{~N})+\mathrm{d}(\% \mathrm{~S})+\mathrm{e}(\%)+\mathrm{f}(\% \mathrm{ash})
$$

Some of the major advantages of using a pulsed neutron generator (instead of a radioisotopic neutron source currently in use).were:

- Direct measurement of carbon (the main element in coal) without interference from other elements;

- Measurement of elements such as oxygen and sodium that cannot be measured with a system based on a radioisotopic neutron source;

- Major reduction of the radiation hazard during removal and transportation of the neutron source;

- Reduction of the background in the gamma-ray spectrum; and

- Ability to utilize a large number of nuclear reactions (fast neutron induced reactions, thermal neutron induced reactions, and neutron activation reactions) which allow improvement of the sensitivity and precision in the measurement of a specific chemical element.

The research was divided in several key components:

- Identify the most suitable nuclear reaction for the measurement of each element;

- Select the appropriate detectors for the detection of the characteristic gamma rays; 
- Design the geometrical configuration for the neutron generator-gamma ray detectors-coal sample system that would make the most efficient use of the measuring parameters;

- Develop the necessary computer codes for the analysis of the gamma ray spectra;

- Design the data acquisition system.

For this multifaceted research project, expertise of several faculty members in various departments including the Department of Chemistry (for ASTM analysis of coal samples) and the Department of Computer Science (use of neural networks for data analysis) was required. Furthermore, several talented undergraduates and graduates were involved in the project. As shown below, these undergraduates had the opportunity to present their work in national meetings, as well as being co-authors in refereed publications.

Besides the pulsed fast, thermal neutron analysis (PFTNA) R\&D, considerable effort was made to correlate the bulk analysis PFTNA results with results obtained from standard laboratory analytical techniques like those from ASTM. This effort included the synthesis of standard and known samples. To alter, for example, the sulfur content of a coal sample, a controlled amount of a sulfur chemical compound was mixed with a $32 \mathrm{~kg}$ coal sample. The mixing of the sulfur was performed with a commercial $\mathrm{V}$ blender used by pharmaceutical companies for powder mixing. The sulfur content of the bulk sample was then measured with PFTNA, and a small sample from the $32 \mathrm{~kg}$ coal sample was analyzed using an ASTM method.

Because carbon is the main chemical element in coal, ranging in content between $40 \%$ to $80 \%$ weigh, its accurate on-line determination is important in gauging coal's calorific value. For uninterrupted on-line measurements, it would be beneficial to be able to measure the carbon content directly, without relying on a calibration obtained from the laboratory analysis of a large number of coal samples - a procedure currently followed with other commercial radio-isotopic PGNAA systems. The monochromatic fast neutrons produced from the neutron generator we employed were suited for gauging the carbon content in coal. The carbon $4.43 \mathrm{MeV}$ photopeak and its single-escape peak are formed with high intensity, and with minimal interference from other peaks. Furthermore, the fast neutron fluence rate in the interrogated coal volume was minimally affected by changes in the elemental composition of coal. For several coal samples, their "fast" spectra were taken and were analyzed. The results of the $\gamma$-ray yields as a function of the carbon content (in weight\%) established through laboratory ASTM analysis showed a linear relation, justifying the assumption that the carbon content of coal could be established without having to re-calibrate the system.

The density of coal is also an important parameter to measure for fossil energy plants. Our PFTNA experimental arrangement measured a given volume of coal irrespective of the amount of coal contained in it. However, coal shipped from the mines to coal preparation plants and coal-fired power plants varies in size between $7.5 \mathrm{~cm}$-to-fines. Thus, the measured volume could contain different amounts of coal depending on the particle size and the on the extent to which gravity settling had occurred during shipment. To compensate for changes in coal density within the measured coal volume, a $\gamma$-ray-based densitometer was designed, utilizing the transmission through coal of a $662 \mathrm{keV}{ }^{137} \mathrm{Cs} \gamma$-ray. A narrowly collimated ${ }^{137} \mathrm{Cs}$ source was placed on the one side of the coal sample, and the transmitted $\gamma$-rays are detected with a collimated $5.1 \mathrm{~cm} \times 5.1 \mathrm{~cm} \mathrm{NaI}(\mathrm{Tl})$ detector. For the $662 \mathrm{keV} \gamma$-ray, the absorption takes place primarily through the Compton effect, which has a Z/A dependence. Since for most of the 
elements contained in coal the $\mathrm{Z} / \mathrm{A}$ ratio is nearly the same (except for $\mathrm{H}$ ), the effective $\mathrm{Z} / \mathrm{A}$ ratio in coal is constant, irrespective of changes that can occur in the elemental composition of coal. This premise was tested for various coal samples whose elemental composition was established through independent ASTM-based analyses. Using multiple coal samples, a densitometer calibration was established using our analysis method.

Coal moisture is also a very important parameter of coal. One of the most commonly used methods for measuring moisture on-line is through microwave absorption. Although it is considered quite efficient and fast, reports from users indicated that microwave-based moisture meters were not very accurate. Furthermore, the microwave technique could be used for moisture measurements of frozen coal. Therefore our PFPTA method was employed to measure moisture, both through measuring the hydrogen gamma-ray peak with fast neutron transmission through coal samples.

This laboratory R\&D was used as background for designing and building a prototype online coal analyzer. The preliminary design included two coal chutes: the main one with a $40 \mathrm{~cm}$ diameter through which coal flowed continuously at a rate of 3-5 tons-perhour, and the auxiliary one with $25 \mathrm{~cm}$ diameter where coal flowed in $8 \mathrm{~kg}$ batches every 30-40 seconds. The neutron generator was located between the two chutes, and fired continuously, $14 \mu \mathrm{s}$-wide neutron pulses having a $14 \mathrm{kHz}$ frequency. Gamma-ray detectors were located around the main chute for the measurement of gamma-rays from fast and thermal neutron excitation. The auxiliary chute was used for neutron activation measurements. The prototype was then used to measure the elemental properties of coal samples received from mining and utility operations.

\section{PROJECT 1 FUNDING:}

DOE: $\$ 577,945$

Commonwealth of KY: $\$ 358,569$

Total Funding DOE + KY: $\$ 936,514$

\section{PUBLICATIONS AND PRESENTATIONS}

L. Dep and G. Vourvopoulos, Pulsed fast and thermal neutron analysis for coal and cement industries, Amer. Inst. of Physics CP392, 861 (1997).

G. Vourvopoulos, A new approach for nuclear on-line coal analysis, presented at the Economic and Environmental Aspects of Coal Utilization Conference, Santa Barbara CA., 2/18/97.

G. Vourvopoulos, Pulsed neutron generator-based system for elemental coal characterization, presented at the 22nd International Technical Conference on Coal Utilization and Fuel Systems, Clearwater, FL, 3/16/97.

Womble, P.C., F.J. Schultz, and G. Vourvopoulos, Non Destructive Characterization Using Pulsed Fast-Thermal Neutrons, Nuclear Instr. \& Methods, B99 (1995) 757. 
K. Lamkin, F. Schultz, P. Womble, D. Humphrey, and G. Vourvopoulos, An application of the RFQ linac: nuclear waste characterization, Amer. Inst. of Physics, CP392, 841 (1997).

G. Vourvopoulos, L. Dep, J. Paschal, and G. Spichiger, PELAN- A transportable, neutron-based UXO identification technique, UXO Forum' 97, 342 (1997).

Vourvopoulos, G., L. Dep, S. Sudar, P.C. Womble, and F.J., Schultz Neutron-Generator Based On-Line Coal Analysis: A Progress Report, Proceedings 8th Intern. Conf. On Coal Science, Oviedo, Spain (Elsevier Science), 1995.

Dep, L. and G. Vourvopoulos, Neutron-Based Elemental Coal Characterization, 12th Intern. Coal Testing Conf. (Vanguard Solutions, Ashland, KY), 1996.

F.J. Schultz, G. Vourvopoulos, P.C. Womble, and M.L. Roberts, A Feasibility Study for a LinacBased Transuranic Waste Characterization System,, J. of Radioanal. and Nucl. Chem. $\underline{193}(1995) 369$.

M. J. Balbes, M.M. Farrell, R.N. Boyd, X. Gu, M. Hencheck, J.D. Kalen, C.A. Mitchell, J.J. Kolata, K. Lamkin, R. Smith, R. Tighe, K. Ashktorab, F.D. Bechetti, J. Brown, D. Roberts, T.F. Wang, D. Humphrey, G. Vourvopoulos, M.S. Islam, Cross Sections and Reaction Rates of $d+^{8} \mathrm{Li}$ Reactions Involved in Big Bang Nucleosynthesis, Nuclear Physics A584(1995)315.

G. Vourvopoulos and J. Thornton, A Transportable, Neutron-Based Contraband Detection System, Proceedings, 1995 ONDCP National Drug Control Policy Symposium (Nashua, NH), 1995.

L. Dep, Coal analysis, American Physical Society, May 1995.

G. Vourvopoulos, Neutrons in Coal Analyisis, 12th Coal Testing Conference, Sept 1996.

\section{ACCOMPLISHMENTS}

Starting in 1994, project under the direction of Dr. George Vourvopoulos at Western Kentucky University constructed and operated a prototype instrument, and demonstrated its usefulness for analyzing critical characteristics of coal. The analyses were accomplished as the coal was transported on a conveyor system and were deemed precise enough for improving operational efficiencies of large coal-fired power plants. The instrument, based on nuclear physics principles, was successfully demonstrated and has been commercialized, the first site application of which is at a $2600 \mathrm{MW}$, Tennessee Valley Authority coal power plant. The instrument provides critical data on nearly $3,000,000$ tons of coal per year that are used in the power plant.

As a consequence of the infrastructure created by this initial Kentucky DOE EPSCoR funding, Dr. Vourvopoulos garnered over $\$ 5,000,000$ in follow-on funding for re-engineering the 
instrument for other applications. Among the funding includes a $\$ 500,000$ grant from the DOE, in cooperation with ORNL scientists, to develop new detection technology for radioactive waste materials; the Office on National Drug Control Policy awarded a $\$ 600,000$ grant; the US Department of Defense provided a $\$ 350,000$ award; and the National Science Foundation (NSF) awarded both Phase I, Small Business Innovative Research (SBIR) contract for $\$ 50,000$ and a Phase II SBIR for $\$ 500,000$. Dr. Vourvopoulos and his team have filed and received patents on their technology developments.

Additionally, the United Nations has purchased an adaption of the on-line coal analysis instrument called PELAN $N_{L M}$ - Pulsed Elemental Analysis by Neutrons for Land Mines. It is used in Hungary by U.N. peace keepers to locate small land mines left after the cessation of hostilities. Another adaption of the instrument called PELAN $N_{C W}$ - Pulsed Elemental Analysis by Neutrons

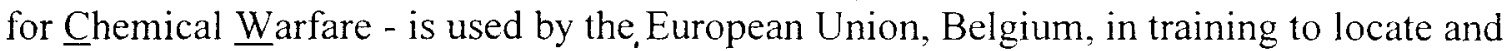
identify chemical agent weapons.

2. Project 2: Investigation of the Behavior of Potentially Hazardous Trace Elements in Kentucky Coals and Combustion Products

PRINCIPAL INVESTIGATOR: F.E. Huggins, Research Professor, Department of Chemical Engineering, University of Kentucky, Lexington, KY 40506

\section{CO-PRINCIPAL INVESTIGATORS:}

B.K. Parekh, Center for Applied Energy Research, University of Kentucky, 2540 Research Park Drive, Lexington, KY 40511 tel (859) 259-0239, fax (859) 257-0207, email parekh@caer.uky.edu

J. David Robertson, Department of Chemistry, University of Kentucky, Lexington, KY 405060055, tel (859) 257-7070, fax (859) 323-1069, email jdrobson@pop.uky.edu

J.K. Neathery, Center for Applied Energy Research, University of Kentucky, 2540 Research Park Drive, Lexington, KY 40511 tel (859) 259-0255, fax (859) 257-0207, email neathery@caer.uky.edu

\section{SUMMARY}

This research project involved the characterization of trace elements in coals and coal combustion byproducts designated as potentially hazardous to human health in the 1990 Amendments to the Clean Air Act. The emphasis in these studies was three-fold:

(i) how do these elements occur in coals, coal fractions, and combustion products;

(ii) how do these elements behave during advanced coal cleaning processes (both physical and chemical); and

(iii) how do these elements behave in dry, triboelectrostatic upgrading of coal and coal combustion byproducts.

The last topic reflected the inclusion of Dr. Heng Ban, an expert in triboelectrostatic separation, into this Research Cluster, starting in Year 3 of the project. However, at the end of the 
fourth year, Dr. Ban accepted a position with Southern Company in Birmingham, AL. He was replaced by Dr. James K. Neathery as co-PI on the project. Dr. Neathery continued the triboelectrostatic research on trace element separation initiated by Dr. Ban.

Dr. Frank Huggins concentrated his investigations into modes of occurrence of elements in coal. Work was done in cooperation with the International Energy Agency (IEA)-sponsored roundrobin testing of modes of occurrence of minor and trace elements in coal. Four coals, one each from the USA, United Kingdom, Australia and Nova Scotia, Canada were distributed to various research groups worldwide for determination of elemental speciation and subsequent assessment of different methods applied to coals to determine elemental speciation. The R\&D concentrated on the use of XAFS spectroscopy to speciate various elements in the four coals.

Dr. Parekh concentrated on beneficiation studies designed to enhance the removal of trace elements from coals. Experiments were conducted on Kentucky No. 9 and Pittsburgh No.8 coals. A combination of advanced gravity and surface chemical processes were applied to determine the extent of trace metals removal from these two coals. It was found that $60 \%$ of $\mathrm{Fe}$ and $\mathrm{Zn}$, about $45 \%$ of $\mathrm{Cu}, \mathrm{Cr}$, and $\mathrm{As}$, and $27 \%$ of $\mathrm{Ni}$ and $\mathrm{Br}$ could be removed at $80 \%$ combustible recovery by subjecting coarsely ground ( $80 \%$ passing 60 mesh) Kentucky No. 9 to separation by a Falcon concentrator, an advanced gravity concentrator. Similarly, Fe, $\mathrm{Zn}$ and Ge in the range of 39 to $44 \%$, and $\mathrm{Cu}$ and $\mathrm{As}$ at about the $31 \%$ level were removed from the Pittsburgh No. 8 coal at a combustible recovery of $85 \%$.

Column flotation of the ultra-fine ground ( $90 \%$ passing 325 mesh) Kentucky No.9 removed about $60 \%$ of $\mathrm{Al}, \mathrm{Si}, \mathrm{K}, \mathrm{Ca}, \mathrm{Mn}, \mathrm{Sr}, \mathrm{Cr}, \mathrm{Zn}$ and $\mathrm{As}$ and $17 \%$ of $\mathrm{Hg}$ at $94 \%$ combustible recovery. For Pittsburgh No.8 coal, about 75 to $85 \%$ of $\mathrm{Mg}, \mathrm{Si}, \mathrm{Ca}, \mathrm{Ti}, \mathrm{Cr}, \mathrm{Mn}$, and $\mathrm{Cu}$, and about $37 \% \%$ of $\mathrm{Hg}$ elements were removed at $94 \%$ combustible recovery.

Oil agglomeration, using hexane of the column product removed an additional $10 \%$ of $\mathrm{Fe}, \mathrm{Zn}, \mathrm{Ge}, \mathrm{As}$ and Sr. A final hydrothermal treatment of the Kentucky No.9 column product with $6 \% \mathrm{HNO} 3$ at $230 \mathrm{~F}$ removed 55 to $70 \%$ of the remaining $\mathrm{Fe}, \mathrm{Zn}, \mathrm{Br}, \mathrm{Sr}, \mathrm{Pb}, \mathrm{Cl}, \mathrm{Ca}, \mathrm{Zr}$ and $\mathrm{Cr}$. The same treatment on the Pittsburgh No. 8 column product removed 25 to $30 \%$ of the remaining $\mathrm{Mg}, \mathrm{Al}, \mathrm{Si}, \mathrm{S}$, and $\mathrm{K}, 45 \%$ of $\mathrm{Cl}$ and $\mathrm{Ca}$, and $60 \%$ of $\mathrm{Zn}$ and $\mathrm{Br}$. For both coals, the combination of Falcon concentrator, column flotation and hydrothermal treatment of the coal successfully removed about 70 to $80 \%$ of many trace elements from the coals.

The focus of the trace-element research with triboelectrostatic separation was largely on mercury partitioning between components in combustion fly-ash products. The main objectives of this work were to (i) demonstrate the partitioning of mercury in dry triboelectric separation systems for beneficiating combustion fly ash; (ii) determine if mercury is contained primarily in either the ash-rich or carbon-rich fractions of fly ash; and (iii) to compare the performance of a continuous pilot-scale separator with that of a small laboratory-scale unit with regard to mercury removal.

The Electric Power Research Institute (EPRI) partially funded the development of a larger-scale dry triboelectric technology at the Center for Applied Energy Research. Using data and engineering assessments from laboratory-scale and bench-scale testing, the technology progressed to the construction of a proof-of-concept (POC) processing platform with an estimated feed rate capacity of $250 \mathrm{~kg} / \mathrm{hr}$. Gas flow-rates, pressure drops, solids/gas mass ratios, operation under recycle or staging, flow distribution into the electric field separator, efficiently 
splitting or extracting high and low LOI products, and the separation efficiency for fly ash processing have been quantified for the POC unit. The unit has also been modified to permit recycling so that clean ash recovery may be optimized.

Fly ash samples from Kentucky Utilities, East Kentucky Power, the Southern Company were subjected to electrostatic separation in the POC unit. Electrostatically-separated fly ash samples showed considerable enrichment of mercury in the carbon-rich fractions (from 3 to 4 times higher than the bulk ash material). The material balances for each of the as received ash separation experiments indicate that mercury generally reports with carbon.

In a related work, collaboration was initiated with personnel at ADA Technologies, Golden, $\mathrm{CO}$, to investigate mercury partitioning in a commercial combustion fly-ash from the Cherokee power plant in Colorado. This particular fly-ash had been demonstrated to have an unusually high propensity for mercury absorption. The triboelectric separation was used to generate fractions of the fly-ash, which have then been examined using Hg XAFS spectroscopy to identify more directly how the mercury is contained in the various fractions. The combination of these techniques showed that the mercury was associated with a specific carbon fraction that is attracted to the negative electrode in the triboelectric separation.

\section{FUNDING}

DOE: $\$ 442,994$

Commonwealth of Kentucky: $\$ 312,470$

Total funding DOE + KY: $\$ 755,464$

\section{ACCOMPLISHMENTS}

Research proposals were submitted to numerous organizations, both federal and industrial, and research collaborations established. The following is a list of these accomplishments leading to sustainability.

1) F.E. Huggins and J.D. Robertson, Environmental Protection Agency; "Chemical Speciation and Source Signatures of Hazardous Air Pollutant Elements in Ultrafine Airborne Particulate Matter", $\$ 471,825$, University of Kentucky.

2) F.E. Huggins, U.S. DOE; "Analytical Signatures of $\mathrm{PM}_{2.5}$ from Petroleum Refining and Fuel Use", $\$ 900,000$, University of Kentucky, University of Utah and West Virginia University.

3) F.E. Huggins, U.S. DOE; "Toxic Substances from Coal Combustion", $\$ 320,200$, University of Kentucky, and Physical Sciences, Inc. (prime), University of Arizona, University of Utah, University of Connecticut, University of North Dakota Energy and Environmental Research Center.

4) J.K. Neathery, Electric Power Research Institute; "Dry Ash Separation: Scale-up of the Triboelectrostatic Process", \$90,000, University of Kentucky.

5) B.K. Parekh, USDOE/FETC Pittsburgh; "Development and Demonstration of Integrated Carbon Recovery Systems from Fine Coal Processing Waste", \$499,982, University of Kentucky, Southern Illinois University, Illinois Geological Survey, Illinois Clean Coal 
Institute, Consol Inc., Falcon Concentrator Company.

6) F. E. Huggins and G. P. Huffman, "Toxic substances from coal combustion -- a comprehensive assessment." Subcontract on U.S. DOE Contract DE-RA22-94PC92291 awarded to Physical Sciences, Inc., $\$ 112,000$.

7) Awards received: F.E. Huggins, G. P. Huffman, and J. D. Robertson: Certificate of Merit, Awarded by American Chemical Society, Division of Environmental Chemistry for the paper "Application of XAFS spectroscopy to the investigation of HAPs elements in particulate matter samples" presented at ACS $216^{\text {th }}$ National Meeting, Boston, MA, August 22 21998.

8) Collaborations established:

R. B. Finkelman, Research Manager, U.S. Geological Survey, Reston, VA.

F. Goodarzi, Research Manager, Geological Survey - Canada, Calgary, AB, Canada.

L. Dale, Research Manager, CSIRO, Sydney, Australia

J. Williamson. Professor, Imperial College, University of London, United Kingdom

R. Killmeyer, Project Manager, USDoE/FETC Pittsburgh, PA.

R. Fernandez, Lab Director, Element Analysis Corporation, Lexington, KY.

C. Senior, Senior Scientist, PSI, Inc.

D. Finseth, Research Scientist, USDoE/FETC Pittsburgh, PA

J. Albiston, Research Scientist, ADA Technologies

B. Manowitz, Research Scientist, Brookhaven National Laboratory, Upton, NY.

\section{PUBLICATIONS \& PRESENTATIONS}

J.K. Neathery, D. Challman, F. Derbyshire and D. Gray, The Pioneer Plant Concept: Co-Production of Electricity and Value-Added Products from Coal, Fuel, Vol. 78, pp. 815-823, 1999.

F.E. Huggins and G. P. Huffman, Element speciation in environmentally important materials, Proceedings, Third Internat. Conf. Mater. Enginer. Resources (Akita, Japan), Plenary \& Keynote Sessions Volume, pp. 382-388, (1998).

F.E. Huggins, N. Shah, G. P. Huffman and J. D. Robertson, XAFS spectroscopic characterization of elements in combustion ash and fine particulate matter, Proceedings, Conf. Air Quality (McLean, VA), 23 pp. (1998).

F.E. Huggins, M. Najih and G. P. Huffman, Direct speciation of chromium in coal combustion byproducts by X-ray absorption fine structure spectroscopy. Fuel (Special Issue, 1997 International Ash Utilization Symposium), $\underline{78}$, 233-242, (1999).

F.E. Huggins, G. P. Huffman, G. E. Dunham and C. L. Senior, XAFS examination of mercury sorption on three activated carbons, Energy \& Fuels, 13, 114-121, (1999).

F.E. Huggins, N. Yap and G. P. Huffman, XAFS Investigation of mercury sorption on carbon-based and other sorbent materials, Jpn. J. Appl. Phys. (Proc. Int. Conf. SRMS-2, Kobe, Japan) 38 (Suppl. 38-1), 588-591, (1999) 
F.E. Huggins, N. Yap, G. P. Huffman and C. L. Senior, Identification of Mercury Species in Unburned Carbon from Pulverized Coal Combustion, Proceedings, Air \& Waste Management Association 92nd. Annual Meeting (St. Louis, MO), Paper 99-A72, (1999).

F.E. Huggins, N. Shah, G. P. Huffman and J. D. Robertson, XAFS spectroscopic characterization of elements in combustion ash and fine particulate matter, Fuel Proc. Technol. (Proceedings, Conf. Air Quality, McLean, VA), (1999).

F. E. Huggins, J. Zhao, N. Shah and G. P. Huffman, Speciation of selected HAPs elements in coal ash. Proceedings, 1997 International Ash Utilization Symposium (Lexington, KY), University of Kentucky Center for Applied Energy Research, pp. 682-689, (1997).

F. E. Huggins, G. P. Huffman and J. D. Robertson, Application of XAFS spectroscopy to the investigation of HAPs elements in particulate matter samples. Preprints Extend. Abstr., ACS Div. Environ. Chem., 38(2), 143-145, (1998).

L.J. Blanchard, J.D. Robertson, S. Srikantapura and B.K. Parekh, PLXE Analysis of the Hydrothermal Leaching of Trace Elements in Coal, J.Radioanal. Nucl. Chem. 221, 23-28, (1997).

L.J. Blanchard and J.D. Robertson, Determination of Mercury in Coal Using Radiochemical Neutron Activation Analysis, The Analyst 122, 1261-1264, (1997).

J.C. Hower, U.M. Graham, A.S. Wong, J.D. Robertson, B.O. Haeberlin, G.A. Thomas and W.H. Schram, Influence of Flue-Gas Desulfurization Systems on Coal Combustion By-Product Quality at Kentucky Power Stations Burning High-Sulfur Coal, Waste Management 17(8), 523-533 (1997).

J.C. Hower, L.J. Blanchard and J.D. Robertson, Magnitude of Minor Element Reduction through Beneficiation of Central Appalachian Coals, J. Coal Prep 19, 213-229, (1998).

Lori Jean Suing Blanchard, "Development and Application of Nuclear Methods for the Analysis of Mercury and Other Trace Elements in Coal," (Ph. D.; Thesis Director: J. David Robertson), University of Kentucky, October, 1997.

Julie Helen Kuhr, "Application of Low-Rank Coal for Removal of Heavy Metal and Radioactive Contaminants from Aqueous Solutions," (Ph. D.; Thesis Director: J. David Robertson), University of Kentucky July, 1998.

F. E. Huggins, J. Zhao, N. Shah and G. P. Huffman, Speciation of selected HAPs elements in coal ash. 1997 International Ash Utilization Symposium, Lexington, KY, October, 1997.

F. E. Huggins, B. K. Parekh, H. Ban, and J. D. Robertson, Overview of Cluster Research Project. 1998 Kentucky State EPSCoR Meeting, Louisville, KY, May 1998. 
J. D. Robertson, et al., Petrology, Mineralogy, and Chemistry of Magnetically-Separated Sized FlyAsh, 1997 International Ash Utilization Symposium, Lexington, KY, October 1997.

J. D. Robertson, Particle-Induced X-Ray Emission, Federation of Analytical Chemistry and Spectroscopy Societies, Providence, RI. (Invited) October 1997.

J.K. Neathery, Triboelectrostatic Separation of Fly Ash: Enrichment of Mercury in High LOI Fractions Annual EPSCoR Conference, Somerset, KY, May 11, 1999.

J.K. Neathery, Technology Development for Carbon-Ash Beneficiation by Pneumatic triboelectric Processing, International Ash Utilization Conference, Lexington, KY, October 18, 1999.

F.E, Huggins and G. P. Huffman, Element speciation in environmentally important materials, Third International Conference on Materials Engineering for Resources, Plenary \& Keynote Session, Akita, Japan, October 26 $6^{\text {th }}, 1998$.

F.E. Huggins, N. Yap and G. P. Huffman, XAFS Investigation of mercury sorption on carbon-based and other sorbent materials, International Conference on Synchrotron Radiation in Materials Science 2, Kobe, Japan, November, $3^{\text {rd }}, 1998$.

F.E. Huggins, N. Shah, G. P. Huffman and J. D. Robertson, XAFS spectroscopic characterization of elements in combustion ash and fine particulate matter, Conference on Air Quality, McLean, VA, December $6^{\text {th }}, 1998$.

F.E. Huggins, Element Speciation in Coal and Ash, Annual EPSCoR Conference, Somerset, KY, May 11, 1999.

F.E. Huggins, S. Srikantapura, B.K. Parekh, L. Blanchard and J.D. Robertson, XANES Spectroscopic Characterization of Selected Elements in Deep-Cleaned Fractions of Kentucky \#9 Coal, Energy \& Fuels, 11, 691-701 (1997).

F. E. Huggins and G. P. Huffman, Modes of occurrence of trace elements in coal from XAFS spectroscopy, Int. J. Coal Geol., 32, 31-53, (1996).

L.J. Blanchard, J.D. Robertson, S. Srikantapura and B.K. Parekh, PLXE Analysis of the Hydrothermal Leaching of Trace Elements in Coal, J. Radioanal. Nucl. Chem. 221, 23-28, (1997).

F. E. Huggins and G. P. Huffman, Application of XAFS spectroscopy to coal geochemistry. In: Mineral Spectroscopy: A Tribute to Roger G. Burns, (eds. M. D. Dyar, C. A. McCammon, and M. W. Schaefer), The Geochemical Society, Houston, TX, Special Publication No. $\underline{5}, 133-151$, 
(1996).

F. E. Huggins, J. Zhao, N. Shah, F. Lu, G. P. Huffman, L. E. Bool, III and C. L. Senior, Investigation of the oxidation of arsenical pyrite in coal and its effect on the behavior of arsenic during combustion, Proceedings, ICCS '97, 9th International Conference on Coal Science, (Essen, Germany), (eds. A. Ziegler, K. H. van Heek, J. Klein, and W. Wanzl), 1, 381-384, P \& W Druck und Verlag GMBH, Essen (1997).

M.-I. M. Chou, J. A. Bruinius, J. M. Lytle, R. R. Ruch, F. E. Huggins, G. P. Huffman and K. K. Ho, The forms of trace metals in Illinois basin coal by X-ray absorption fine structure spectroscopy, Preprints, ACS Div. Fuel Chem., 42(4), 1113-1117, (1997).

F. E. Huggins, G. P. Huffman, G. E. Dunham and C. L. Senior, XAFS examination of mercury capture on three activated carbons, Preprints, ACS Div. Fuel Chem., 42(4), 118-122, (1997).

J.C. Hower, J.D. Robertson, A.S. Wong, C.F. Eble and L.F. Ruppert, Arsenic and Lead Concentrations in the Pond Creek and Fire Clay Coal Beds, Eastern Kentucky Coal Field, Applied Geochemistry 12, 281-289 (1997).

J.H. Kuhr, J.D. Robertson, C.J. Lafferty, A.S. Wong and N.D. Stalnaker, Ion Exchange Properties of a Western Kentucky Low-Rank Coal, Energy \& Fuels, 11, 323-326 (1997).

\section{STUDENT SUPPORT AND THESIS}

N.W-L, Yap, B.Eng., Chemical and Materials Engineering, University of Kentucky, 2000.

C.L. Jones, B. Eng., Chemical and Materials Engineering, University of Kentucky, 2001.

R.S. Devarakonda, M. Eng, Mining Engineering, University of Kentucky, 1999.

S. Young, PhD, Chemistry, University of Kentucky, 2000.

G. Peterson, B.S., Chemistry, University of Kentucky, 1999.

J. Shergur, B.S., Chemistry, University of Kentucky, 1999.

3. Project 3: Supporting Technologies for Effective Use of On-line Analyzers in the Control of Coal Quality

PRINCIPAL INVESTIGATOR: Jon C. Yingling, Mining Engineering, University of Kentucky, Lexington, KY 40506, tel (859) 257-1105, fax (859) 323-1962, email jyingling@eng.uky.edu

\section{CO-PRINCIPAL INVESTIGATORS:}

Joseph Sottile, Jr., Mining Engineering, University of Kentucky, Lexington, KY 40506, Tel (859) 257-4616, fax (859) 323-1962, email jsottile@engr.uky.edu 
Ratnesh Kumar, Electrical Engineering, University of Kentucky, Lexington, KY 40506, tel (859) 257-6143, fax (859) 257-3092, email rkumar@engr.uky.edu

\section{SUMMARY}

The Clean Air Act imposes strict standards on the quality of coal to utilities. To enable mine operators to meet these stricter specifications, on-line analyzers may potentially serve as key components in selective coal extraction, segregation, processing, sortation, and blending systems. With proper facility design and control strategies, these systems could meet demanding coal quality specifications with reduced coal cleaning costs, increased coal recovery, and reduced generation of mine wastes.

The supporting technologies needed to fully use on-line analyzers in control of coal quality are far less developed than are the analyzers themselves. This project addressed two important supporting technologies. First, a model for tracking the migration of coal horizons through core-flow silos was refined and tested through laboratory studies. Such a model is a critical need in blending control systems. Second, a control approach for optimal coal sortation/segregation was developed.

The model developed treats the coal as rigid-plastic. In the flow zone, or plastic region, the solid is assumed to be isotropic, frictional, and cohesive. Stress conditions under steady-state flow are characterized by an effective yield locus, which describes plastic failure without dilation. Flow along silo walls is characterized by a wall yield locus. In addition to the effective yield locus and the wall yield locus, the model is determined by (1) equilibrium equations relating the physical coordinate system with stresses and bulk density, (2) the equation of continuity of a continuous medium relating velocities with the coordinate system, and (3) an assumption of isotropy which leads to coincidence of the direction of principle stresses and strain rates. Under suitable assumptions regarding boundary conditions, the model consists of a system of hyperbolic partial differential equations that may be solved by the method of characteristics first for the stress field and subsequently for the desired velocity field.

Our work developed a process for physical segregation of coal that utilizes existing online coal quality analyzers. This process enables a substantial fraction of unprocessed, run-ofmine (r.o.m.) coal to bypass coal-cleaning processes to a no-wash stock, saving in coal cleaning costs and avoiding losses of combustibles inherent in all coal cleaning operations. The no-wash stock is intended to meet customer quality specifications without the need for cleaning.

Accordingly, a control objective of the segregation system is to insure that the average quality characteristic of the no-wash stock meets or exceeds customer specifications. We called this target control. In addition, in order to maximize the economic benefit of the process, it is also desired to maximize the fraction of the coal sent to no-wash. We called this maximizing yield.

We discovered that it is appropriate to view the observed quality measurements as a manifestation of a non-stationary stochastic process (i.e., a system where the observed values are random and, because of non-stationarity, the nature of the randomness -- e.g., the mean, variance, auto-correlation, or distribution -- changes with time). Our procedure utilizes the observed quality measurements to partition time into intervals where the process is locally stationary. The distribution of coal quality is characterized in that interval of time, and a criterion that we have developed is applied to make segregation decisions that meet target value while maximizing 
yield. Yield maximization is only "local" for the interval of time in question, although our tests show that yields are often close to theoretical maximum values that could be obtained if the ultimate distribution of coal quality levels could somehow be know a priori.

A number of variants of our algorithms were refined and new variants were developed. The work was brought to a stage where we could achieve target control with reasonable consistency and realize high yields. These variants differ in the ways for interval partitioning, estimating the local behavior of the process and parameter updating.

We tested our procedure using field data as recorded by the ash analyzer that monitors the run of mine coal stream at the Nelms Mine, Harrison Mining Company, Cadiz, OH. Our procedures exhibited strong abilities in target control and yields generally approach theoretical maximums as it would perform in segregating 96,000 tons of coal. Any case where customer specifications were exceeded by 0.05 wt. \% ash was considered to "fail" since such coal could not be directly shipped to the customer. Yield was then summed for all of the successful cases for each of the control procedures. Our methods met target on a much higher frequency and in cases where both our method and the industrial method met target, our yields were much higher. The different variants of the process performed better in different circumstances and we have identified these circumstances. We also note that case studies show that certain variants of our procedures worked when the coal on the mine-mouth conveyor was a random mix of coals from two different production sections underground.

\section{FUNDING}

DOE: $\$ 67,920$

Commonwealth of KY: $\$ 40,184$

Total funding DOE + KY: $\$ 108,104$

\section{ACCOMPLISHMENTS}

- In practical situations of coal flow there is a discontinuity in the stress field brought about by the intersection between the top surface of the coal in the silo and the side wall. A procedure was established for propogating the stress field solution across this discontinuity and it was coded and tested numerically. The results appeared reasonable and empirical validation was accomplished.

- A procedure was established for tracking bulk material flow through a laboratory scale silo that provides sequence information of flow from particular points within the silo. This procedure was.tested in several runs and will be used in future model validation tests.

- Assuming a priori knowledge of the distribution of coal quality during a control period, a criterion for optimal coal segregation, i.e., segregation that satisfies quality targets while maximizing the amount of no-wash coal, was established. This criterion serves as a basis for all of our segregation algorithms. 
- Numerous datasets were obtained from a cooperating mine and analyzed using time series and other statistical approaches. It was determined that non-stationary behavior of the system was prevalent and must be accommodated in any control strategy.

- Two control strategies were established. Both approaches accommodate non-stationarity by attempting to estimate a distribution descriptive of the "current" behavior of the process. The criterion mentioned above is then used as a basis for a decision to on whether to send the coal unit to wash or no-wash. Such an approach has the feature that, assuming accurate estimation of the local behavior of the process, desired coal quality targets should be met over time. However, there is no guarantee that yields will be optimal except when behavior is stationary. The first approach uses (non-stationary) time series models to estimate the local behavior. The second approach uses empirical distributions that are updated on a rolling horizon basis.

- The two control strategies were extensively evaluated. It was determined that the time series approach works poorly in general for the mine under study because of a particular type of heteroskedasticity where the variance of the process increases with the mean of the process. Simple correction techniques were devised and the performance of the strategy improved markedly. It was also determined that the time series approach will fail when the process takes certain forms. This was only observed once in our field datasets and is not believed to be a major limitation of the method. The empirical distribution approach worked quite well in general. Both the corrected time series and empirical distribution approaches were comparable in performance. Moreover, both approaches showed dramatic performance advantages over control approaches used in industry today in both yield and ability to meet quality targets.

- The field data have focused our interest in the development of more sophisticated models of the stochastic nature of the process. In particular we are currently investigating the use of heteroskedastic models where both the mean and variance of the process are nonstationary and viewed as a function of time. Importantly, such models may transcend our reliance on a local description of the process in making segregation decisions and allow us to use a global (i.e., long term) description in making these decisions. This should enable improved yields if successful.

\section{PUBLICATION AAND PRESENTATIONS}

R. Ganguli, J.C. Yingling, S. Zhang. and R. Kumar, R., 1999, Optimal Control of Coal Segregation using On-line Quality Analyzers, Mining Engineering, 51, 41-47(1999).

Ganguili, R., Yingling J., Sottile, J., Kumar, R., Algorithms for Physical Segregation of Coal, Annual Kentucky EPSCoR Conference, May 11, 1999, Somerset,KY

R. Ganguli, and J.C. Yingling, Optimal Control of Coal Segregation Using On-line Quality Analyzers, SME/AIME Annual Meeting, March 9-11, 1998, Orlando, FL. 
R. Ganguli, New Developments in Control of Coal Segregation Using On-line Ash Analysis, CAS/SME Regional Meeting, June 6, 1998.

R. Ganguli and Yingling, J.C., Algorithms for Physical Coal Segregation, Central Appalachian Section SME Spring Meeting, June 1999, Abingdon, VA.

\section{COLLABORATIONS}

Mr. John McNab, Executive Vice President and Chief Operation Officer, Harrison Mining Company in Cadiz, $\mathrm{OH}$.

\section{IV.b. Environmental Science Research}

1. Project 1: Transport. Accumulation and Utilization of Organic Carbon in Large $\underline{\text { Reservoir Svstems }}$

PRICIPAL INVESTIGATOR: Dr. George W. Kipphut, Murray State University, Center for Reservoir Research, Murray, KY 42071; tel (270) 762-2847; email george.kipphut@murraystate.edu

\section{CO-PRINCIPAL INVESTIGATORS:}

Dr. Susan P. Hendricks, Murray State University, Department of Biological Sciences, Murray, KY 42071, tel (270) 762-6365; email: susan.hendricks@murraystate.edu

Dr. Timothy C. Johnston, Murray State University, Department of Biological Sciences, Murray, KY 42071, tel (270) 762-6367; email: tim.johnston@murraystate.edu

Dr. Thomas C. Kind, Murray State University, Mid-America Remote Sensing Center, Murray, KY 42071, tel (270) 762-3110; email: tom.kind@murraystate.edu

Dr. Burl I. Naugle, Murray State University, Department of Geosciences, Murray, KY 42071, tel (270) 762-3105; email: burl.naugle@murraystate.edu

Murray State University, Department of Biological Sciences, Murray, KY 42071, tel (270) 7626326 email: jim.sickel@murraystate.edu

David S. White, Murray State University, Hancock Biological Station, Murray, KY 42071, tel (270) 474-2272; email: david.white@murraystate.edu

Stephen B. White, Murray State University, Department of Biological Sciences, Murray, KY 42071, tel (270) 762-6298; email: steve.white@murraystate.edu 
Paul A. Bukaveckas, University of Louisville, Department of Biology, Louisville, KY 40292, tel (502) 852-3726; email: pabuka01@athena.louisbville.edu

Lee W. Cooper, Environmental Sciences Division, Oak Ridge National Laboratory, present address: University of Tennessee, Department of Ecology and Evolutionary Biology, Knoxville, TN, 37996, tel (865) 974-2990; email: lcooper@utkux.utcc.utk.edu

\section{SUMMARY}

Research in this cluster has included faculty and staff participants from Murray State University, the University of Louisville, and the Oak Ridge National Laboratory. The overall focus of the interdisciplinary research has been processes that regulate the transport, deposition, and transformation of organic carbon in large reservoir systems. The focus on organic carbon provides a natural link between the physical structure of reservoirs, diverse ecological relationships, and water quality.

The primary research sites were two of the largest reservoirs in the Southeastern United States. Kentucky Lake is an impoundment of the Tennessee River created in 1944. Lake Barkley was created by impoundment of the lower Cumberland River in 1964. A large data set has been obtained defining biogeochemical processes affecting the cycling of carbon in Kentucky Lake, the largest reservoir within the Tennessee River Valley.

Among the goals achieved are: 1) determined organic carbon and total sediment accumulation rates; 2) determined rates of chemical transformations that affect carbon accumulation; metabolism, and mineralization; and 3) determined rates of sediment-biotic interactions which affect, and in turn are regulated by, fluxes of organic carbon. We also constructed a carbon budget for Kentucky Lake and have begun to understand the relations between sedimentary processes and the distribution and activities of biological organisms.

Since impoundment in 1944, we estimate that sedimentation has resulted in accumulation of 7.5 million tons of carbon and 750 million tons of total sediment within the lower $60 \mathrm{~km}$ of Kentucky Lake. Despite the high rates of sediment accumulation, the concentrations of sedimentary carbon and nitrogen are quite low. As a result, the macrobenthic fauna is poorly developed in most locations and is dominated by surface gatherers (chironomids) and surface suspension feeders (pelecypods), rather than by deposit feeders (oligochaetes). Water column primary productions rates are large during summer months. However, most of this production is apparently transported out of the reservoir or remineralized near the sediment-water interface with little net accumulation in the sediments. Measured rates of bacterial production and nutrient and dissolved gases fluxes are quite high within the sediments and appear to be related to water temperature.

FUNDING:

DOE: $\$ 566,588$

Commonwealth of Kentucky: $\$ 359,531$

Total DOE + KY funding: $\$ \$ 26,119$ 


\section{ACCOMPLISHMENTS}

As a consequence of the DOE EPSCoR funding, the following have been accomplished:

- Environmental science infrastructure in the Commonwealth of Kentucky has been dramatically improved and postdoctoral, graduate and undergraduate training in this area has been promoted

- Determined that 750 million tons of sediment and 7.5 million tons of carbon have accumulated in the lower $60 \mathrm{~km}$ of Kentucky Lake Reservoir since impoundment in 1944

- Demonstrated that Kentucky Lake Reservoir is supersaturated with respect to carbon dioxide and methane and is an atmospheric source for these greenhouse gases.

- Determined that most of the carbon incorporated by primary production is transported out of the system or remineralized within the sediments.

- Demonstrated the application of remotely sensed data to the study of suspended sediments in large reservoirs.

- Supported the research of 8 M.S. students at (7 at Murray State University, and 1 at the University of Louisville), and 2 Ph.D. students at the University of Louisville.

- $\quad$ Provided research experiences and support for more than 12 undergraduate students at Murray State University.

- $\quad$ Supported the research efforts of 4 post-doctoral research associates. All have subsequently found permanent employment within academia (2), government (1), and private industry (1).

- $\quad$ Research grants were generated by the faculty supported in DOE EPSCoR, including:

1. White, D.S., Hendricks, S.P., Kipphut, G.W., and T.C. Johnston. A Comparison of Agricultural vs Forested Basins: Carbon and Nutrient Cycling within the Hyporheic Ecotone of Streams, U.S. Environmental Protection Agency, Amount: $\$ 300,000$, November 1995-October 1999.

2. Hendricks, S., Jack, J., Kipphut, G., and White, D. Reservoir-Watershed Linkages: the Effects of Water Level Management on Hydrology and Water Quality in Hydro-electric Reservoirs. U.S. Department of Energy/Kentucky EPSCoR Program. \$43,000, October 1999-December 2001.

3. Whiteman, H., Hendricks, S., Johnston, T., Kipphut, G., Loganathan, B., Owen, D., Spencer, W., and Timmons, T. Collaborative Research at Undergraduate Institutions: Biogeochemical and Ecological Processes within a Reservoir Littoral Zone. National Science Foundation. \$789,000, December 1999-November 2003.

4. Kipphut, G., S. Cetin, H., Hendricks, S., Kemp, M., Loganathan, B., White, D., and Whiteman, H. Infrastructure for a Center for Watershed Environments at Murray State University. Proposal pending with the National Science Foundation EPSCoR Program. Amount \$1,500,000, January 2002-December 2004.

\section{PUBLICATIONS AND PRESENTATIONS}


D.J. Berg, W.R. Haag, S.I. Guttman, and J.B. Sickel. 1995. Mantle biopsy: a technique for nondestructive tissue-sampling of freshwater mussels. J. N. Amer. Benthological Soc. 14(4):577581

H.N. Blalock and J.B. Sickel. 1996. Changes in mussel (Bivalvia: Unionidae) fauna within the Kentucky portion of Lake Barkley since impoundment of the lower Cumberland River. Amer. Malacol. Bull. 13:111-116.

J. Butrick, 1999. Analysis of noise reduction routines applied to LandSat TM datasets. M.S. Thesis. Murray State University.

Halda-Alija, L., S.P. Hendricks, and T.C. Johnston. In Press. Spatial and temporal variation of Enterobacter populations in sediments and underlying hyporheic zone of an agricultural stream. Microbial Ecology.

Halda-Alija, L., and T.C. Johnston. 1999. Diversity of culturable heterotrophic aerobic bacteria in pristine stream bed sediments. Can. J. Microbiol. 45:879-884.

Hendricks, S.P. 1998. Bacterial abundance and productivity within the hyporheic sediments of the Shingobee River in northcentral Minnesota: a summary report of 1996-1997 results to the U.S. Geological Survey, Menlo Park, CA.

Herod, J.J., T.L. Frye, and J.B. Sickel. 1997. Blue catfish predation on the zebra mussel in the Ohio River near Paducah, Kentucky. Trans. Ky. Acad. Sci. 58(2): 96.

Kazwell, J.L. 1996. Comparison of two non-point source pollution models utilizing Geographic Information Systems. M.S. Thesis, Murray State University, 105 p.

Rao, M.B. 1999. Mapping of suspended sediments in Kentucky Lake using LandSat TM data. M.S. Thesis, Murray State University.

Reed, D.P., J.J. Herod, and J.B. Sickel. 1998. Variations in zebra mussel (Dreissena polymorpha) veliger densities throughout 1996 at Dam 52 on the lower Ohio River. Journal of Freshwater Ecology 13(3):255-261.

Richard, H.M. 1999. Distribution of carbon dioxide and methane in Kentucky Lake Reservoir: seasonal, spatial, and long-term patterns. M.S. Thesis, Murray State University, 88 p.

Richard, K.A. 2000. Total suspended solids, turbidity, and chlorophyll-a relationships in Kentucky Lake Reservoir defined with monitoring and remotely sensed data. M.S. Thesis, Murray State University. 
Sickel, J.B. 1998. Gluttonous feeding behavior in the Rhabdocoel, Macrostomum sp., induced by juveniles of the Asiatic clam, Corbicula fluminea. Journal of Freshwater Ecology 13(1): 135137.

Sickel, J.B. and C.C. Chandler. 1996. Unionid fauna of the lower Cumberland River from Barkley Dam to the Ohio River, Kentucky (Mollusca: Bivalvia: Unionidae). Trans. Ky. Acad. Sci. 57:33-46.

Sickel, J.B., J.J. Herod, and H.N. Blalock. 1996. Biological assessment of the commercial mussel resources in Kentucky and Barkley Lakes, Kentucky. Report to Kentucky Department of Fish and Wildlife Resources, Frankfort, KY. 82 pp.

Williams, J. 1999. Regulation of phytoplankton and bacterioplankton production by nutrient availability and advective losses in a large river impoundment (Kentucky Lake). M.S. Thesis. University of Louisville.

Yurista, P.M., K. Johnston, G. Rice, G.W. Kipphut, and D.S. White. In Press. Particulate organic carbon patterns in a mainstem reservoir, Kentucky Lake, USA. Lake and Reservoir Management.

Brinkley, K.A., J.B. Sickel, and L. Duobinis-Gray. 1998. Gonad development in zebra mussels (Bivalvia: Dreissenidae) from the Tennessee and Ohio Rivers. Presentation at the Southern Division of the American Fisheries Society 1998 Midyear Meeting, Lexington, KY, February 27 March 1, 1998.

Brinkley, K., J. Sickel, L. Duobinis-Gray, and J. Herod. 1997. Histological analysis of gonad development in Zebra Mussels from the Tennessee and Ohio Rivers. Proceedings of the seventh symposium on the natural history of the lower Tennessee and Cumberland River Valleys.

Halda-Alija, L., G. L. Ridout, and T. C. Johnston. 1997. Microbial diversity and activity in the sediments of Kentucky Lake. Annual meeting of the American Society for Microbiology, Miami, Florida.

Halda-Alija, L., G. L. Ridout, and T. C. Johnston. 1997. Structure and function of microbial communities in agricultural vs. forested streams. In: Gordon Research Conference, Applied and Environmental Microbiology, Newport, RI.

Hendricks, S.P., G.W. Kipphut, and G. Ridout. 1998. Bacterial productivity and dissolved nutrient flux in sediments of Kentucky Lake, a Tennessee River valley reservoir. American Society of Limnology and Oceanography. St. Louis, MO. 
Herod. J., D. Reed, and J. Sickel. 1997. Distribution and population characteristics of Zebra Mussels in Kentucky Lake, Kentucky. Proceedings of the seventh symposium on the natural history of the lower Tennessee and Cumberland River Valleys.

Kind, T., S. White, and C. Davis. 1997. Sedimentation in the lower reaches of Kentucky Lake, 1946-1995. Proceedings of the seventh symposium on the natural history of the lower Tennessee and Cumberland River Valleys.

Kipphut, G.W., and H.M. Hoe. 1998. Sediment-water chemical interactions in a large reservoir. American Society of Limnology and Oceanography. St. Louis, MO.

Kipphut, G.W., T.C. Johnston, and G.L. Ridout. 1996. Sediment-water chemical exchange in Kentucky Lake Reservoir. American Society of Limnology and Oceanography. Milwaukee, WI.

Kipphut, G.W., T.C. Johnston, and G.L. Ridout. 1997. Measurement of sediment-water chemical exchange rates in Kentucky Lake Reservoir. $17^{\text {th }}$ International Symposium of the North American Lake Management Society. Houston, Texas.

Kipphut, G.W., H.M Richard, and W.C. Colburn. 2001. Carbon dioxide and methane concentrations in reservoir and stream environments in the lower Tennessee River Valley: seasonal and long-term patterns. $21^{\text {st }}$ International Symposium of the North American Lake Management Society.Madison, WI.

Kipphut, G.W., H.M. Richard, and G.L. Ridout. 1999. Sediment-water fluxes of nutrients and dissolved gases in Kentucky Lake Reservoir. American Society of Limnology and Oceanography. Santa Fe, NM.

Kipphut, G.W., H.M Richard, G. Ridout, and T. Ray, 2001. Sediment-water fluxes of nutrients and dissolved gases in Kentucky Lake Reservoir. Proceedings of the ninth symposium on the natural history of the lower Tennessee and Cumberland River Valleys, Brandon Springs, TN.

Kipphut, G., G. Ridout, T. Johnston, H. Hoe, and S. Hendricks. 1997. Sediment-water chemical exchange in Kentucky Lake Reservoir. Proceedings of the seventh symposium on the natural history of the lower Tennessee and Cumberland River Valleys.

Kipphut, G.W., D.S. White, T.C. Kind, and S.P. Hendricks. 1999. Transport and accumulation of sediment and carbon in Kentucky Lake Reservoir. $19^{\text {th }}$ International Symposium of the North American Lake Management Society. Reno, NV.

Leek, D. 1996. Cycling of organic carbon in Kentucky Lake. $2^{\text {nd }}$ Annual meeting of Kentucky EPSCoR. Louisville, KY. 
Moyer, D.A., D.S. White, G. Kipphut, and L.W. Cooper. 1998. Benthos-sediment relationships in a main stem reservoir, Kentucky Lake, USA. American Society of Limnology and Oceanography. St. Louis, MO.

Palmer, W., L. Yuan, and S.P. Hendricks. 1997. Demonstration of a WindowsTM user interface to expedite solute transport modeling using OTIS. American Society of Limnology and Oceanography. Albuquerque, NM.

Reed, D., J. Herod, and J. Sickel. 1997. A comparison of larval development in Zebra Mussels up to the free-swimming Trochophore stage in Tennessee and Ohio River water. Proceedings of the seventh symposium on the natural history of the lower Tennessee and Cumberland River Valleys. Brandon Springs, TN.

Reed, D.P., J.J. Herod, and J.B. Sickel. 1998. Annual variations in zebra mussel (Dreissena polymorpha) veliger densities throughout 1996 at Dam 52 on the lower Ohio River. Southern Division of the American Fisheries Society 1998 Midyear Meeting, Lexington, KY.

Ridout, G. L. and T.C. Johnston. 1996. Identification of important microbial biogeochemical sequences. $2^{\text {nd }}$ Annual meeting of Kentucky EPSCoR. Louisville, KY.

Ridout, G. L. and T.C. Johnston. 1996. The microbial diversity of Kentucky Lake Reservoir sediments. American Society of Limnology and Oceanography. Milwaukee, WI.

Ridout, G., L. Halda-Alija, and T. Johnston. 1997. Structure and function of microbial communities in Kentucky Lake sediments. Proceedings of the seventh symposium on the natural history of the lower Tennessee and Cumberland River Valleys. Brandon Springs, TN.

Ridout, G. L., L. Halda-Alija, and T. C. Johnston. 1997. Structure and function of microbial communities in Kentucky Lake Sediments. North American Benthological Society. San Marcos, TX.

Sickel, J.B., J.J. Herod, and D.P. Reed. 1998. Impact of zebra mussels and commercial mussel harvest on native unionid mussels in Western Kentucky. Southern Division of the American Fisheries Society 1998 Midyear Meeting, Lexington, KY.

Sickel, J. B., J. J. Herod and H. B. Ruez. 1995. Potential for the Kentucky Dam tailwater of the Tennessee River to serve as a mussel refuge from invading zebra mussels. UMRCC Symposium: Conservation and Management of Freshwater Mussels II, Initiatives for the Future. Sponsored by Upper Mississippi River Conservation Committee and U.S. Fish and Wildlife Service. St. Louis, MO. 
Sickel, J.B., J.J. Herod, and D.P. Reed. 1998. Impact of zebra mussels and commercial mussel harvest on native unionid mussels in Western Kentucky. Presentation at the Southern Division of the American Fisheries Society 1998 Midyear Meeting, Lexington, KY.

\section{AWARDS}

Outstanding Teacher Award at Murray State University, awarded to Dr. George Kipphut, Environmental Science Cluster Principal Investigator, May 2001.

2. Project 2: Reservoir-Watershed Linkages: The Effects of Water Level Management on Hydrology and Water Quality in Hydro-Electric Reservoirs

PRINCIPAL INVESTIGATOR: Dr. Susan P. Hendricks, Murray State University, Department of Biological Sciences, Murray, KY 42071, tel (270) 762-6365; email:

susan.hendricks@murraystate.edu

\section{CO-PRINCIPAL INVESTIGATORS:}

Dr. George W. Kipphut, Murray State University, Center for Reservoir Research, Murray, KY 42071; tel (270) 762-2847; email george.kipphut@murraystate.edu

Dr. Timothy C. Johnston, Murray State University, Department of Biological Sciences, Murray, KY 42071, tel (270) 762-6367; email: tim.johnston@murraystate.edu

Dr. Thomas C. Kind, Murray State University, Mid-America Remote Sensing Center, Murray, KY 42071, tel (270) 762-3110; email: tom.kind@murraystate.edu

\section{SUMMARY}

This project was funded by Kentucky DOE EPSCoR during 1999-2000 as a development effort at Murray State University in cooperation with the University of Kentucky. It was part of an effort by the KY DOE EPSCoR Program to provide seed funding to some peer reviewed research such that a competitive position could be established for innovative and sustaining research and, if so, it was to be included in the Kentucky response to a DOE EPSCoR solicitation for Implementation Grants in 2000.

During the first year it begun investigations into the effects of reservoir levels' rise and fall on groundwater hydrology, biogeochemistry and microbial ecology at the floodplainreservoir interface and on reservoir water quality. Objectives of the developmental project included increased collaborative research among the institutions involved in the study, increased research opportunities for undergraduate and graduate students and post-doctoral researchers, and increased infrastructural support for sustaining competitive research in Kentucky.

The long-term scientific goals of the research were to initiate collaborative research in the fields of hydrology, biogeochemistry and microbial ecology and to understand the effects of 
hydro-power management on reservoir water quality. It would test the hypothesis that, as reservoir levels rise and fall, subsurface water movement into and out of tributary floodplains alters groundwater hydrology, biogeochemistry and microbial ecology of the floodplain and ultimately reservoir water quality. Research infrastructure objectives of the proposed research included 1) building collaborative faculty research relationships among Murray State University, University of Kentucky and Oak Ridge National Laboratory to accomplish research that would not otherwise be done, 2) to provide research opportunities for undergraduate and graduate students from MSU and UK and for post-doctoral researchers, and 3) to enhance the infrastructural support for sustaining competitive research in Kentucky. The tasks accomplished during Year 1 will set the stage for full project proposal development during ensuing years (Years 2 and up to four years beyond) if the project was included in our response to a DOE EPSCoR solicitation in 2000 and if it was funded by the DOE.

\section{ACCOMPLISHMENTS}

The project developed preliminary data directed at putting together a proposal for the DOE EPSCoR solicitation. Upon submitting it along with the other proposed research clusters to the DOE, it was not selected for funding by the USDOE. The momentum gained as a consequence of Kentucky DOE EPSCoR support provided a beginning infrastructure and interdisciplinary approach that led to proposals and funding outside of DOE EPSCoR (see funding under Project 1 in Environmental Research)

\section{IV.c. High Energy and Nuclear Physics Research}

1. Project 1: High Energy Physics Research

PRINCIPAL INVESTIGATORS: Keh-Fei Liu, Dept. of Physics and Astronomy, University of Kentucky, Lexington, KY 40506; tel (859) 257-4849; email liu@pa.uky.edu

\section{CO-PRINCIPAL INVESTIGATORS}

Terrence Draper, Department of Physics and Astronomy, University of Kentucky, Lexington, KY 40506, tel (859) 257-3413, email draper@pa.uky.edu

Clifford Johnson, Department of Physics and Astronomy, University of Kentucky, Lexington, KY 40506, tel (859) 257-4957, email cvj@pa.uky.edu

Bing An Li, Department of Physics and Astronomy, University of Kentucky, Lexington, KY 40506 tel (859) 257-1486, email li@ukcc.uky.edu

Raphael Finkel, Department of Computer Science, University of Kentucky, Lexington, KY 40506 tel (859)257-3416, email raphael@cs.engr.uky.edu 
Alfred Shapere, Department of Physics and Astronomy, University of Kentucky, Lexington, KY 40506 tel (859) 257-8896, email shapere@pa.uky.edu

Michael Crescimanno, Department of Physics and Astronomy, Youngstown State University, Youngstown, OH 44555, email: mcrescim@cc.ysu.edu

\section{SUMMARY}

This research cluster upgraded and enhanced high-energy physics and parallel supercomputing in Kentucky. The research program included the study of the structure of the proton and neutron and heavy-light mesons. With simulations on parallel computers to perform lattice gauge Monte Carlo calculations, we studied nucleon form factors (electromagnetic, axialvector, scalar, and pseudoscalar) and other hadron properties in order to compare with experiments, to test models and to make predictions. These are ab initio calculations based on Quantum Chromodynamics (QCD), the fundamental theory of the strong interaction. The program also included the study of effective theories of QCD as well as analytic solutions of the supersymmetric QCD and string theory.

Also, we developed computing platforms and algorithms on massively parallel systems. Collaboration between computer scientists and computational physicists to develop efficient parallel application software was one of the goals of the development program.

\section{CLUSTER FUNDING}

DOE: $\$ 473,857$

Commonwealth of Kentucky: $\$ 280,131$

Total: $\$ 753,988$

\section{ACCOMPLISHMENTS}

- $\quad$ Hiring of faculty members and staff

a) A new faculty member, Alfred Shapere, was hired and joined the physics department of University of Kentucky in August 1994. He was chosen among 156 well-qualified applicants. His specialty is in mathematical physics and he has worked on topological lattice field theory which complements the main thrust of our project in lattice gauge calculation very well. His achievements in physics was amply recognized by the award of the Sloan Fellowship in 1995.

b) We successfully hired a staff computational scientist, Shao-Jing Dong, in the computer center. Dr. Dong job was to help us move some of our lattice calculations to the newly acquired parallel Convex-HP Exemplar computer on campus which has a peak speed of 8 Gflops.

c) A minority faculty member, Clifford Johnson, was hired in 1997, and then subsequently left the University in 2001 . He was an outstanding theorist working in string theory and black holes. 
- Degrees Granted and Follow up on Students

a) Chris Thron, an EPSCoR trainee, obtained his Ph. D. in 1997 and is working in Texas Instrument as a staff engineer.

b) Joseph Christensen, obtained his Ph. D. in 1997 and is a faculty member at McMurry University, Abilene, TX.

c) Madhu Sudan obtained his Ph. D. in 1998. His thesis was on multicast in heterogenous networks with different receiver-specified QoS. He was employed by SRI, and now works for CISCO.com.

d) Jun Gao obtained her Ph. D. in 2000 and is working in the Silicon Valley as a computer scientist.

e) Ioan Popescu obtained his Ph. D. in 2001 and is now a postdoctoral researcher at the Vancouver Island Cancer Centre in Victoria, British Columbia.

f) Adel Awad obtained his Ph. D. in 2001 and is now a postdoc in the high energy physics group at the University of Cincinnati.

g) Ping Zhang obtained his Masters in 1997, with a thesis on "Object-oriented libraries for dynamically parallel computation with PVM". He is working at Lexmark, Lexington, $\mathrm{KY}$.

h) Dheerendra Talur received his Masters in 1998. He is working at FORE Systems.

i) Sachin Mullick obtained his Masters in 1998. He is working at SCO Unix in Berkeley Heights, NJ.

j) Anthony Borchers received his Masters in 1998; his topic of research was "Scout, A rule-invoking web-crawler". He was employed at Lexmark in Lexington, KY and then moved to work for PowerVision in Delray Beach, FL.

k) Lei Shen obtained his Masters in 1999; the topic of his thesis was "KATR project". He is employed by RSW Software.

l) Vishaka Aggarwal obtained a Masters in 1999 on the "X multiplexer", and is now employed by Computer Associates, Cincinnati.

m) Dhaval Shah received a Masters in 1999 on "Mush enhancements", and is now working at Oracle, Redwood City, CA.

n) Gopala Tumuluri received a Masters in 1999 on "Reliable transport over ATM", and is now employed by Marconi (formerly called FORE), Pittsburgh, PA.

o) Nan Guo received a Masters in 2000 on "Database explorer", and is now employed by Celera Genomic, Foster City, CA.

p) Christopher Dotson received a Masters in 2000 on "NT Administration Tools", and is now working at IBM in Lexington, KY.

q) Sandip Shah received a Masters in 2000 on "UTP protocols in Linux", and is now at Marconi (formerly called FORE) in Pittsburgh, PA.

r) Himanshu Shah obtained a Masters in 2000 on "LDAP as a SAT Backend", and is now at CISCO systems, San Jose, CA.

s) Rukmangathhan Balakrishnan earned a Masters in 2000 on "A Pseudo Distributed File System", and is now at CISCO systems, San Jose, CA.

t) Calthur G. Harish Kaushik earned a Masters in 2000 working on "NFS 3 for Linux", and is now at Wind River, Alameda CA. 
u) Uma Krishnan earned a Masters in 2000 on "JDBC for QDDB", and is now working at the Dow Jones, New York, NY.

v) Huar-En Ng earned a Masters in 2000 on "Suda On Line", and is now at Computer Associates.

- Nine undergraduates were involved in the funded research with Micheal Crescimanno.

- Lattice QCD calculation of Nucleon Structure (K.F. Liu): Together with Shao-Jing Dong, Terrence Draper, Frank Lee, Ivan Horvath, and Jianbo Zhang, we have successfully implemented the overlap fermion calculation of meson and baryon properties. This is a new action which has chiral symmetry on the lattice. We have been granted 500,000 CPU-hours at the NSF center at UCSD and 550,000 CPU-hours at NERSC to carry out our numerical calculation.

- $\quad$ Lattice Calculation of Heavy-Light Mesons (T. Draper): C. McNeile (postdoc), Joe Christensen (graduate student), and T. Draper have been studying heavy-quark effective theories on the lattice. Probing strongly-interacting particles with a static color source is the most direct way of studying the non-perturbative dynamics of quarks and gluons at long distances. We have applied novel variational techniques we developed to a calculation of the matrix element relevant for calculating differences in the lifetimes of neutral B-mesons. In addition to our numerical work, which we showed to be an order of magnitude more efficient than some competing methods, we proposed a method to isolate and stabilize sensitivity in the analytical calculations (lattice perturbation theory) necessary to convert these to experimental predictions. This has been published as an extensive 20-page manuscript in Physical Review D.

- $\quad$ Chiral Theories of Hadrons (B.A. Li): An effective chiral theory of 2 and 3 flavors is developed for the mesons and is successful in delineating low energy properties. New sum rules are derived and the coefficients of the chiral perturbation theory are being calculated. The results are published in 4 papers in Physical Review D.

- Supersymmetric QCD (A. Shapere and M. Crescimanno): Alfred Shapere continued his research into the structure of supersymmetric quantum chromodynamics (SQCD). Extending methods developed by Seiberg and Witten, he and Philip Argyres found exact solutions for theories with classical gauge groups and arbitrarily many flavors of quarks. Together with Ronen Plesser, they also determined the vacuum structure of these theories in the Coulomb and Higgs phases. With Michael Crescimanno, Shapere initiated a study of critical behavior in SQCD.

- $\quad$ Distributed Computation (Raphael Finkel): Raphael Finkel has been concentrating on platforms for distributed computation over a wide range of problem domains, including QCD. The Canopy platform is in use on the Exemplar. I have also been developing the DIB platform on networks of workstations. This platform allows tree-structured computations to be effectively distributed to balance load dynamically. We have been 
using this platform to investigate the distributed scalability of algorithms for solving constraint-satisfaction problems that arise out of graph theory and scheduling theory.

- Research grants were awarded, including the following:

1. PI: Keh-Fei Liu, Co-PI: Terrence Draper, DOE grant no. DE-FG05-84ER40154

"Theoretical Nuclear Physics", Feb. 1, 1995 --- Jan. 31, 1998, \$330,000; Feb. 1, 1998 -Jan. 31, 2001, \$463,000.

2. R. Finkel, Co-Principal Investigator with Mirek Truszczynski, on 1995 Kentucky Natural Resources and Environmental Protection Cabinet proposals, "Implementing Information Resources", 10/15/95-2/15/96, \$9,000.

3. R. Finkel, Co-Principal Investigator with Mirek Truszczynski and Wiktor Marek on 1995 Defense EPSCoR proposal on "Research in String-Oriented Databases", 7/1/96-6/30/99, $\$ 144,000$.

4. R. Finkel, Co-Principal Investigator with Jim Griffioen, Jim Lumpp, and Raj Yavatkar on 1995 Defense EPSCoR proposal MIS 9508031602. "A scalable distributed multicomputer for massively parallel applications", 7/1/96-6/30/99, $\$ 496,000$ with university matching $\$ 255,000$.

5. R. Finkel, Co-Principal Investigator with Mirek Truszczynski, Raj Yavatkar, and Jim Griffioen on 1995 NSF Infrastructure proposal DA-9502645, "A Laboratory for Research in High Performance Distributed Computing", 7/15/95-6/30/2000, $\$ 1,000,000$ with university matching $\$ 400,000$.

6. A. Shapere, NSF Grant No.PHY9722147, "'Exact Methods in Supersymmetric Gauge Theories and String Theory," 6/97 -- 6/00, \$27,000/yr.

7. Clifford Johnson, DOE Career Grant, 7/98 -- 6/02, $\$ 220,000$.

8. A. Shapere, "Exact Methods in Supersymmetric Gauge Theories and String Theory", NSF Individual Grant No. PHY-9722147 "Exact Methods in Supersymmetric Gauge Theories and String Theory", $\$ 81,000,6 / 15 / 97-5 / 31 / 01$.

9. B. A. Li, DOE grant, 8/00 -- 8/03, $\$ 200,000$.

10. M. Crescimanno, NSF EPSCoR Research Enhancement Grant, $\$ 12 \mathrm{~K}\{1999\}$; National College Science Award, Cottrell Research Corporation, \$12K, 2001 and 1995; Cluster Ohio Program of the Ohio Supercomputer Center, co-PI, $\$ 70 \mathrm{~K}$.

11. R. Finkel, C-PI with Mirek Truszczynski and Wiktor Marek, NSF, "Nonmonotonic reasoning and computational knowledge", 7/2001-7/2004, \$550,000.

\section{PUBLICATIONS AND PRESENTATIONS}

Bing An Li, Chiral theory of mesons, Phys. Rev. D52, 5165-5183(1995).

Bing An Li, Chiral theory of mesons, Phys. Rev. D52, 5184-5193(1995).

T. Draper, C. Nenkov, and M. Peardon, Lattice Gauge Autocorrelations with Anisotropic Action Nucl. Phys. B53 (Proc. Suppl.), 997 (1997). 
J. Christensen, T. Draper, and C. McNeile, A Study of the Static-Light B_B Parameter, Nucl. Phys. B53 (Proc. Suppl.), 378 (1997).

T. Draper and C. McNeile, B-Meson Matrix Elements from Various Heavy Quark Effective Theories, Nucl. Phys. B47 (Proc. Suppl.), 429 (1996).

S. J. Dong, J. F. Lagae, and K. F. Liu, Flavor-singlet from Lattice QCD, Phys. Rev. Lett., 75, 2096-2099 (1995).

P.C. Argyres and A.D. Shapere, The Vacuum Structure of Super QCD with Classical Gauge Groups," Nuclear Physics B461 (1996) 437.

Eric H. Herrin, II and Raphael A. Finkel, "Schema and Tuple Trees: An Intuitive Structure for Representing Relational Data", Computing Systems, Volume 9, Number 2, Spring 1996.

Raphael A. Finkel, "What is an Operating System?" Computing Surveys, March 1996.

Raphael A. Finkel, "The Chimaera Experience" TCOS Bulletin on Operating Systems Education, Volume 8, Number 3, Fall 1996.

Bing An Li, Theory of tau mesonic decays, Phys. Rev. D55, 1436-1452 (1997).

Bing An Li, Tau mesonic decays and strong anomaly of PCAC, Phys. Rev. D55, 14251435(1997).

G.N.Gao, Bing An Li, M.L.Yan, Electromagnetic splittings, Phys.Rev. D56, 4115-4132 (1997).

J. Christensen, T. Draper, and C. McNeile, A Calculation of the B_B Parameter in the Static Limit Phys. Rev. D56, 6993-7011 (1997).

J. Christensen, T. Draper, and C. McNeile, Lattice HQET Calculation of the Isgur-Wise Function, Nucl. Phys. B68 (Proc. Suppl.), 377 (1998).

S.J. Dong, T. Draper, W.C. Kuo, K.F. Liu, C. Nenkov, M. Peardon, J. Sloan, and B.L. Young, Glueball Matrix Elements on Anisotropic Lattices, Nucl. Phys. B68 (Proc. Suppl.), 254 (1998).

S. J. Dong, J. F. Lagae, and K. F. Liu, Pion Nucleon Sigma Term, Strangeness Content, and Scalar Form Factor -- A Lattice Study, Phys. Rev. D54, 5496 -- 5500 (1996).

C. S. Lam and K. F. Liu, Consistency of the Baryon-Multimeson Amplitudes for Large QCD, Phys. Rev. Lett., 79, 597 (1997).

Clifford V. Johnson, From M-Theory to F-Theory, with Branes, Nucl. Phys. B507 (1997) 227. 
Clifford V. Johnson, On the Orientifolding of Type II NS-Fivebranes, Phys. Rev. D56 (1997) 5160.

Nick Evans, Clifford V. Johnson and Alfred D. Shapere, Orientifolds, Branes, and Duality of 4D Gauge Theories, Nucl. Phys. B505 (1997) 251.

C. V. Johnson and R. C. Myers, Aspects of Type IIB Theory on ALE Spaces, Phys. Rev. D55 (1997) 6382.

P.C. Argyres, M.R. Plesser, and A.D. Shapere, Duality from Super QCD with Classical Gauge Groups," Nuclear Physics B483 (1997).

Raphael A. Finkel, "Pulsar: An extensible tool for monitoring large Unix sites, IEEE Software Practice and Experience, Volume 27 Number 10, October 1997.

Amy Levy and Raphael Finkel, Measure of efficiency on heterogeneous machines, University of Kentucky Computer Science Department, Technical Report 271-97, May, 1997.

A. D. Shapere, "Solitons, duality, and supersymmetric gauge theories," Kingston 1997, Solitons, $241-251$.

A. Shapere, "What can supersymmetric gauge theories and string theory learn from each other?," Proceedings of APCTP - ICTP Joint International Conference (AIJIC 97) on Recent Developments in Nonperturbative Quantum Field Theory, Seoul, Korea, 26-30 May 1997.

N. Evans, C. V. Johnson and A. D. Shapere, "Orientifolds, branes, and duality of 4D gauge theories," Nucl.Phys.B. 505, 251 (1997).

A. M. Awad and C. V. Johnson, "Higher dimensional Kerr-AdS black holes and the AdS/CFT correspondence," Phys. Rev. D, 63, 124(2001).

A. M. Awad and C. V. Johnson, "Scale vs. conformal invariance in the AdS/C FT correspondence," Phys. Rev. D, 62, 125(2000).

A. M. Awad and C. V. Johnson, "Holographic stress tensors for Kerr-AdS black holes" Phys. Rev. D, 61, 084(2000).

Raphael A. Finkel, "Pulsar: An extensible tool for monitoring large Unix sites," Software Practice and Experience, 27(1997).

K. Lakshman, Raj Yavatkar, Raphael Finkel, "Integrated CPU and Network I/OoS Management in an Endsystem", Computer Communications, 21, 325 (1998). 
P. Zhang, T. W. Wu, R. Finkel, "Parallel computation for acoustic radiation in a subsonic nonuniform flow with a coupled FEM/BEM formulation" Engineering Analysis with Boundary Elements, 23, 139(1998).

Raphael Finkel, Brian Sturgill, Harlan Stenn, "Experience with a Unix System-Administration Tool", Software Practice and Experience, 29, 953(1999).

Raphael Finkel, William Hutton, Patrick Rourke, Ross Scaife, and Elizabeth Vandiver, "The Suda on Line", Syllecta Classica, Volume 11 (2000).

Bing An Li, "Theory of tau-mesonic decays", Phys.Rev.D55,1436(1997).

Bing An Li, "Tau mesonic decays and strong anomaly of PCAC", Phys.Rev.D55,1425(1997).

D.N.Gao, Bing An Li, and M.L.Yan, "Electromagnetic mass splitting of pi - Kl", Phys.Rev., D56, 4115(1997).

Bing An Li, "Axial-vector currents and tau mesonic decays", Nucl.Phys.Proc.Suppl., 55C, 205(1997).

Bing An Li, "Tau-rho-pi-pi decays", Phys.Rev.D (1998).

M. Crescimanno, C. G. Koay, R.Peterson and R. Walsworth "Analytical estimate of the critical velocity for vortex creation trapped Bose condensates," Phys. Rev. A62, 063612(2000).

M. Crescimanno,C. G. Koay and R. Peterson, "Limits to sympathetic evaporative cooling of a two-component Fermi gas," Phys. Rev. A, 61, 53602(2000).

T. Draper, Status of Heavy Quark Physics on the Lattice, Nucl. Phys. B (Proc. Suppl.) 73, 43 (1999) .

J. Christensen, T. Draper, and C. McNeile, A Calculation of the B_B Parameter in the Static Limit, Phys. Rev. D56, 6993(1997).

J. Christensen, T. Draper, and C. McNeile, Lattice HQET Calculation of the Isgur-Wise Function, Nucl. Phys. B63 (Proc. Suppl.), 377(1998).

S.J. Dong, T. Draper, W.C. Kuo, K.F. Liu, C. Nenkov, M. Peardon, J. Sloan, and B.L. Young, Glueball Matrix Elements on Anisotropic Lattices, Nucl. Phys. B63 (Proc. Suppl.), 254 (1998).

C. Thron, K. F. Liu, S. J. Dong, and H. P. Ying, Padl'e-Z_2 Estimator of Determinants, Phys. Rev. D57, 1642 (1998). 
C.S. Lam and K.F. Liu, Consistency of the Baryon-Multimeson Amplitudes for Large-N_c QCD, Phys. Rev. Lett. 79, \{597 (1997).

L. Lin, K. F. Liu, and J. Sloan, "A Noisy Monte Carlo algorithm", Phys. Rev. D61, 74505 (2000).

K. F. Liu, " Parton Degrees of Freedom from the Path-Integral Formalism", Phys. Rev. D62, $074501(2000)$.

B.A.Li, Effective chiral theory of mesons, Proc. of Intern. Symp. on Particle Theory and Phenomenology, P.341, Ames, Iowa, 5/22-5/24,1995.

B.A.Li, Revisit Weinberg's Sum Rules, Proc. of Intern. Europhysics Conf. on High Energy Physics, p.225, edited by J.Lemmone, Brussels, Belgium, 7/27-8/2,1995.

B.A.Li, Effective chiral theory of mesons, Proc. of Intern. Europhysic Conf. on High Energy Physics, p.79, edited by J.Lemmone, Brussels, Belgium, 7/27-8/2, 1995.

B.A.Li, Axial-vector currents and tau mesonic decays, Proc. of the fourth Intern. Workshop on tau Lepton Physics, p.205, Este Park, Colorado, 9/15-9/19, 1996.

T. Draper, T. Draper, C. Nenkov, and M. Peardon, SU(3) Lattice Gauge Autocorrelations with Anisotropic Action, Nucl. Phys. B53 (Proc. Suppl.), 997 (1997).

f) C. McNeile, J. Christensen, T. Draper, and C. McNeile, A Study of the Static-Light B_B Parameter Nucl. Phys. B53 (Proc. Suppl.), 378 (1997).

K. F. Liu, Nucleon Structure from Lattice QCD, Plenary talk at Annual APS Meeting, May 2, 1995.

K. F. Liu, Nucleon Structure from Lattice QCD, Plenary talk at 3rd Int. Conf. on Computational Physics, Chunyuen, Taiwan, Nov. 13 -- 17, 1995.

A. Shapere, "Gauge Theory of Swimming and Diving," seminar at Nara Women's University, Japan (5/96).

T. Draper, J. Christensen, T. Draper, and C. McNeile, Lattice HQET Calculation of the IsgurWise Function, Nucl. Phys. B68 (Proc. Suppl.), 377 (1998).

S.J. Dong, T. Draper, W.C. Kuo, K.F. Liu, C. Nenkov, M. Peardon, J. Sloan, and B.L. Young, Glueball Matrix Elements on Anisotropic Lattices, Nucl. Phys. B68 (Proc. Suppl.), 254 (1998).

K. F. Liu, Anatomy of Flavor-Singlet g_A, QCD Euroconference 97, Montpellier, 7/3-7/9, 1997. 
K. F. Liu, Valence QCD and Quark Model, QCD Workshop, Bonn, 7/28 - 7/31, 1997.

K. F. Liu, Valence QCD and Quark Model, Int. Sym. on Trends in Sub-Atomic Physics, 8/7 8/12, 1997.

K. Lakshman, Raj Yavatkar, Raphael Finkel, Integrated CPU and Network I/O QoS Management in an Endsystem, IFIP Fifth International Workshop on Quality of Service, 5/21-5/23, 1997.

C. Johnson, "Duality, Geometry and Field Theory", Invited talk presented at the 1997 Symposium on New Trends in Fundamental Physics, National Taiwan University, Taipei, Taiwan. 8/7 - 8/12,1997.

A. Shapere, "Scaling Behavior of Supersymmetric QCD," seminar at Cornell University, (11/96).

A. Shapere, "Gauge Theory of Deformable Bodies: The Geometry of Swimming and Diving," UK Department of Mathematics Colloquium (1/97).

A. Shapere, "Nontrivial Fixed Points in Supersymmetric Field Theories," invited talk at 22nd Karpacz Winter School, Karpacz, Poland (2/97).

A. Shapere, "Solutions of Supersymmetric Gauge Theories," seminar at Ohio State University (3/97).

A. Shapere, "What can supersymmetric gauge theories and string theory learn from each other?" invited talk at the Joint Asia-Pacific Center for Theoretical Physics/International Centre for Theoretical Physics Conference on Recent Developments in Quantum Field Theory, Seoul (5/97).

A. Shapere, "String Theoretic Interpretation of Seiberg Dualities," seminar at Yukawa Institute of Theoretical Physics, Kyoto University (6/96).

A. Shapere, "Solitons in Supersymmetric Gauge Theories," invited talk at Workshop on Solitons, Kingston, Ontario (7/97).

A. Shapere, "Introduction to Seiberg--Witten Theories,"' seminar at University of Montreal, Montreal, Quebec (7/97).

A. Shapere, "New Realizations of Supersymmetric Gauge Theories," invited talk at International Symposium on Trends in Subatomic Physics, Taipei (8/97). 
T. Draper, Quenched Chiral Behavior of Hadrons with Overlap Fermions, Poster presented at Lattice 2001, International Symposium on Lattice Field Theory, Berlin, Germany, 9/19 - 8/24, 2001.

T. Draper, Status of Heavy Quark Physics on the Lattice, Invited plenary review (one-hour) presentation, Lattice '98, International Symposium on Lattice Field Theory, Boulder, Colorado, July 15,1998 .

T. Draper, Lattice HQET Calculation of the Isgur-Wise Function, Poster presented (by J. Christensen, Ph.D. student) at Lattice '97, International Symposium on Lattice Field Theory, Edinburgh, Scotland, July 23, 1997.

T. Draper, Glueball Matrix Elements on Anisotropic Lattices, Poster presented (by C. Nenkov, student) at Lattice '97, International Symposium on Lattice Field Theory, Edinburgh, Scotland, July 23, 1997.

A. Shapere, "Critical Behavior of Supersymmetric Gauge Theories", University of Cincinnati $(5 / 98)$.

A. Shapere, Colloquium: "QCD and String Theory: A Grand Convergence", UK Department of Physics and Astronomy (10/98).

A. Shapere, Colloquium: "Swimming Microbes and Falling Cats: A Gauge Theory of SelfPropulsion", West Virginia University (4/99).

A. Shapere, Colloquium: "Critical Behavior of Supersymmetric Gauge Theories", Massachusetts Institute of Technology (10/00).

A. Shapere, "BPS Equations, BPS States, and Central Charge of Seiberg-Witten Theories", Massachusetts Institute of Technology (2/01).

A. Shapere, "Black Hole Production by Cosmic Rays", University of Kentucky, 9/01.

M. Crescimanno, "Analytical Estimate of Vortex Pair Nucleation by a Moving Stirrer," 2001 Division of Atomic, Molecular and Optical Physics of the American Physical Society Meeting, London, Ontario.

M. Crescimanno, "Dilute alkali BEC critical velocity bound," OSAPS, U. Toledo, 10/13, 2000

M. Crescimanno, "Critical Velocity and Vortex Creation in Bose Condensates," June 26, 2000, Division of Atomic, Molecular and Optical Physics of the American Physical Society Meeting, University of Connecticut 
M. Crescimanno, "Estimating the Critical Velocity in Trapped Bose Condensates," March 21, and 24, 2000. Harvard-Smithsonian CFA and Massachusetts Institute of Technology, Cambridge, MA.

M. Crescimanno, "Critical Velocity from Vortices in Inhomogeneous BEC," June 6, 1999, Gordon Conference on Atomic Physics, Manchester, NH.

K. F. Liu, "Valence QCD and Quark Model", QCD Workshop, Bonn, 7/28 - 7/1, 1997.

K. F. Liu, "Valence QCD and Quark Model", International Symposium on Trends in Sub-Atomic Physics, Taipei, 8/7 - 8/12, 1997.

K. F. Liu, "Parton Degrees of Freedom from Path-Integral Formalism", 2nd Joint Meeting of Chinese Physical Societies, Taipei, 8/11 - 8/15, 1997.

K. F. Liu, "Valence Quark Model from Lattice QCD", Workshop on Chiral Dynamics,Mainz, 9/1 $-9 / 5,1997$.

K. F. Liu, "Valence QCD and Quark Model", Workshop on N Physics, Trento, 5/18 -5/ 22, 1998.

K. F. Liu, "Valence QCD and Lattice Results", International Conference on High Energy Physics, Vancouver, 7/23 - 7/30, 1998.

K. F. Liu, "Flavor-spin Structure of Nucleon from Lattice Calculations", Division of Nuclear Physics Annual Meeting, Santa Fe, 10/28 - 10/31, 1998.

K. F. Liu, "A Noisy Monte Carlo Algorithm", Workshop on Lattice QCD, Adelaide, Australia, $12 / 7-12 / 12,1998$.

K. F. Liu, "Valence QCD and Quark Model", Plenary talk, Joint US-Japan Workshop on Photon-Hadron Physics, Honolulu, Hawaii, 2/22 - 2/25, 1999.

K. F. Liu, "Lattice QCD Computation", Workshop on Computational Sciences and Networking, Hsinchu, Taiwan, 6/21-6/23, 1999.

K. F. Liu, "Parton Degrees of Freedom from Path-Integral Formalism", Plenary talk, Gordon Conference on Nuclear Physics and QCD, Newport, 7/19 - 7/24, 1999.

K. F. Liu, "Noisy Monte Carlo Algorithm with Fermion Determinant", Workshop on Numerical Challenges in Lattice QCD, Wuppertal, Germany, 8/22 - 8/24, 1999.

K. F. Liu, "Noisy Monte Carlo Algorithm with Fermion Determinant", Workshop on Chiral Gauge Theory, Taipei, Taiwan, 9/13 - 9/18, 1999. 
K. F., Liu, "Sea-quark from Lattice Perspective", Workshop on Sea-quarks and Hadron Physics, U. Conn. 11/11 - 11/13, 1999.

K. F. Liu, "Strangeness Content in Nucleon", Plenary talk at V Int. Conf. on Strangeness in Quark Matter, Berkeley, CA., 7/20 - 7/25, 2000.

K. F. Liu, "A Noisy Monte Carlo Algorithm with Fermion Determinant", Physics in New Millennium Conference, Hong Kong, 7/31 - 8/4, 2000.

K. F. Liu, "Finite Density Algorithms", Workshop on a New Computing Venue for Lattice Gauge Theory Calculations, Brookhaven Nat. Lab., 10/12 - 10/14, 2000.

AWARDS

Dr. Alfred Shapere, University of Kentucky, received the prestigious Sloan Fellowship in February 1995.

Dr. K. F. Liu, University of Kentucky, was elected to be a Fellow of the American Physical Society in 1997.

Dr. R. Finkel, University of Kentucky, was elected the Student ACM Professor of the Year award, 1997.

Dr. Clifford, University of Kentucky, was awarded a DOE career grant in 1998.

Dr. R. Finkel had 269 citations for in 2000.

Dr. B. A. Li. Has more than 200 citations.

Dr. M. Crescimanno was elected to be an ITP (Santa Barbara) Scholar for the period 1998-2001.

Project 2: $\quad$ Experimental Nuclear Physics at CEBAF

PRINCIPAL INVESTIGATORS: Dr. Tim Gorringe, tel (859) 257-8740, e-mail

gorringe@pa.uky.edu; Dr. Dan Dale,tel (859) 257-2504; e-mail dale@pa.uky.edu; Dr. Michael Kovash, tel (859) 257-4083; e-mail kovash@pa.uky.edu; Dr. Wolfgang Korsch, tel (859) 257-4083; e-mail korsch@pa.uky.edu

All investigators are at the University of Kentucky, Department of Physics and Astronomy, Lexington, KY 40506

SUMMARY 
The goal of our DOE/EPSCoR project has been to establish a strong, competitive and self--sustaining research program at the Thomas Jefferson National Accelerator Facility. Specifically, we undertook major responsibilities in the development of the Hall A Möller polarimeter (led by Dr. Daniel Dale) and polarized ${ }^{3} \mathrm{He}$ target (led by Dr. Wolfgang Korsch), and the growth of a University of Kentucky spin physics research program at the Jefferson Lab.

The Möller polarimeter is a permanent part of the beamline instrumentation in Hall $\mathrm{A}$ at Jefferson Lab. The polarimeter utilizes electron-electron (Möller) scattering, exploiting the scattering asymmetry for polarized electrons. The University of Kentucky responsibilities included design and development of detector electronics and acquisition software, design and construction of the magnetic elements of the Möller spectrometer, and computer simulations of the interactions of the primary beam and secondary radiation in the Möller polarimeter.

During the 96-97 period the construction and installation of the major components was completed, and commissioning was performed with the electron beam at Jefferson Lab. The Möller. polarimeter detector was constructed and tested at the University of Kentucky, and delivered to Jefferson Lab. This detector consisted of a set of lead-glass Cherenkov detectors and plastic scintillator counters.

The data acquisition electronics for the Möller polarimeter was tested at the university and subsequently installed at Jefferson Lab. This electronics included detector readout and fast coincidence logic. Refurbishment of the major magnetic elements was completed and the magnets were delivered to Jefferson Lab. These included three quadrupole and one dipole magnet as well as a magnetic shielding insertion. In addition, the associated vacuum system was assembled at the university and delivered to Jefferson Lab.

All major components of the polarimeter were assembled on the beamline in the early summer of 1997, and preliminary commissioning with polarized beam was successfully performed. The polarization asymmetry in Möller scattering was demonstrated, and the polarimeter was used in an experiment to study spin transfer in the oxygen nucleus.

In fall of 1996 Dr. Wolfgang Korsch was hired as an EPSCoR funded research assistant professor. He has since become tenured within the Physics Department. Dr. Korsch was strongly involved in the development of a polarized ${ }^{3} \mathrm{He}$ target for Hall $\mathrm{A}$. The first experiment using a polarized ${ }^{3} \mathrm{He}$ in Hall A occurred 1998.

The EPSCoR grant allowed the intermediate energy nuclear physics group of the University of Kentucky to play a leading role in the development of this target. Dr. Korsch also set up a test lab at the University where he now performs systematic target polarization studies. A complete set of equipment for calibration studies using water nuclear-magnetic-resonance (NMR) techniques has also been installed. Dr. Korsch also was responsible for getting undergraduate students involved in his projects.

Both the polarized ${ }^{3} \mathrm{He}$ target and the Möller polarimeter remain essential elements of the beamline instrumentation in Hall A. These instruments, and the University involvement through faculty, staff and students, would not have been possible without Kentucky DOE EPSCoR Program support.

\section{PROJECT FUNDING}


DOE: $\$ 556,980$

Commonwealth of Kentucky: $\$ 360,294$

Total DOE + KY funding: $\$ 917,274$

\section{ACCOMPLISHMENTS}

- Designed, constructed and now operate a Moeller polarimeter for Hall A at Thomas Jefferson National Laboratory.

- Numerous national and international experiments completed utilizing the Moeller polarimeter.

- Developed and optimized polarized helium-3 target for Thomas Jefferson National Laboratory; it has been used for four experiments.

- Detailed studies on and optimized helium-3 polarimetry using NMR and EPR techniques.

- Designed, constructedi and now commissioning of TJNAF Hall B pair production luminosity monitor

- Research grants outside of EPSCoR funding were received. These include the following:

Dr. D. Dale, PI, "Studies of Hadronic Structure Using Electromagnetic Probes", University of Kentucky, $\$ 397,000,02 / 01 / 99-01 / 31 / 02$.

National Science Foundation Major Research Instrumentation Grant, D. Dale, A. Gasparian, R. Miskimen, and S. Danagoulian, "Development of a High Resolution Detection System for Precision Measurements of the Neutral Pion Lifetime at Jlab" $\$ 960,000,08 / 01 / 00$ 07/31/02.

Civilian Research and Development Grant, D. Dale and V. Gorbenko, "Improvement of the Target for the Moller Polarimeter", \$4970, 10/01/00-3/31/02.

Muon Physics and Pion Physics at TRIUMF, Dr. T. Gorringe and Dr. M. Kovash, National Science Foundation, $\$ 460,000,7.01 / 94-6 / 30 / 97 ; \$ 270,000,7 / 1 / 94-6 / 30 / 97 ; \$ 310,000$, $7 / 1 / 97-6 / 30 / 00$.

\section{PUBLICATIONS AND PRESENTATIONS}

B.A. Moftah, E. Gete, D.F. Measday, D.S. Armstrong, J. Bauer, T.P. Gorringe, B.L. Johnson, B. Siebels and S. Stanislaus; "Muon capture on ${ }^{28}$ Si", Phys. Lett. B, 395 (1997) 157.

D.S. Armstrong, J. Bauer, J. Evans, B.L. Johnson, S. Kalvoda, R. Porter, B. Siebels, E. Gete, D.F. Measday, B.A. Moftah and S. Stanislaus, "Muon capture by silicon-28", Hyperfine Interactions, 103(1996)169.

G. Jonkmans, S. Ahmad, D.S. Armstrong, G. Azeulos, W. Bertl, M. Blecher, C.Q. Chen, P. Depommier, B. Doyle, T. von Egidy, T.P. Gorringe, P. Gumplinger, M.D. Hasinoff, A.J. Larabee, J.A. Macdonald, S.C McDonald, M. Munro, J.-M. Poutissou, R. Poutissou, B.C. Robertson, D.G. Sample, E. Saettler, C. Sigler, G.N. Taylor, D.H. Wright and N.-S. Zhang "Radiative Muon Capture on Hydrogen and the Induced Pseudoscalar Coupling", Phys. Rev. Lett. 77 (1996) 4512. 
B. Johnson, T.P. Gorringe, J. Bauer, M. Kovash, R. Porter, D.S. Armstrong, M.D. Hasinoff, D.F. Measday, B.A. Moftah, and D.H. Wright, "Observables in muon capture on ${ }^{23} \mathrm{Na}$ and effective couplings", Phys. Rev. C54 (1996) 2714.

D. S. Dale, "A Moller Polarimeter for Hall A of TJNAF", Polarized Targets and Beams, Seventh International Workshop, Urbana, IL, 1997.

D. Jordan, T. McIlvain, R. Alarcon, R. Beck, W. Bertozzi, V. Bhushan, W. Boeglin, J.P. Chen, D. Dale, G. Dodson, S. Dolfini, K. Dow, J. Dzengeleski, M.B. Epstein, M. Farkhondeh, S. Gilad, J. Gorgen, M. Holtrop, K. Joo, J. Kelsey, W. Kim, R. Laszewski, R. Lourie, J. Mandeville, D. Margaziolis, D. Martinez, R. Miskimen, C.N. Papanicolas, S. Penn, W. Sapp, A.J. Sarty, D. Tieger, C. Tschalaer, W.Turchinetz, G. Warren, L. Weinstein, and S. Williamson, "A Measurement of the Longitudinal, Transverse, and Longitudinal-Transverse Structure Functions in the D(e,e'p)n Reaction", Phys. Rev. Lett. 76,(1996)1579.

E.J. Beise, D.H. Beck, E. Candell, R. Carr, F. Duncan, T. Forest, W. Korsch, J.W. Mark, R.D. McKeown, B.A. Mueller, M.Pitt, S. Wells, "A High Power Liquid Hydrogen Target for Parity Violation Experiments", Nucl. Instr. Meth. A378 (1996) 383.

W. Korsch, R.W. Carr, A. Dvoredsky, R.D. McKeown, Y. Li, M.L. Pitt, D. DeSchepper, L.H. Kramer, R.G. Milner, S.F. Pate and T. Shin, "Temperature Dependence of ${ }^{3} \mathrm{He}$ Polarization In Aluminum Storage Cells"; Nucl. Instr. Meth. A389(1997)389.

B. Mueller et al. (The SAMPLE Collaboration), "Measurement of the Proton's Neutral Weak Magnetic Form Factor”, Phys. Rev. Lett. 78(1997)3824.

A. Ackerstaff, et al. (The HERMES Collaboration), "Measurement of the Neutron Spin Structure Function g1(n) with a Polarized He-3 Internal Target" Phys. Lett. B404(1997)383.

W.Korsch, "Strange Currents in the Nucleon", Proc. of the XIV ${ }^{\text {th }}$ International Conference on Particles and Nuclei, World-Scientific (1996).

B.D. Anderson, A.R.Baldwin, W. Bertozzi, T. Buti, A. Fazely, M. Finn, C.C. Foster, W. Glockle, J. Golak, M.A. Kovash, R. Kurmanov, R. Madey, B. Murdock, P.C. Tandy, J.W. Watson and H. Witala, "Cross-section measurements for the ${ }^{2} \mathrm{H}(\mathrm{p}, \mathrm{n})^{2} \mathrm{p}$ reaction at $135 \mathrm{MeV}$, Phys. Rev. C54,1531(1996).

S. Sawada, T. Hasegawa, N. Horikawa, S. Ishimoto, T. Iwata, M. Kawabata, Y.D. Kim, M.A. Kovash, Y. Mizuno, F. Nakayama, H. Ogami, A. Ogawa, T. Sasaki, T.-A. Shibata, K. Tamura and J. Trice, "Differential Cross Sections for $\mathrm{np}->\mathrm{dx}$ at 1.0 and $2.0 \mathrm{GeV}$ ", Nucl. Phys. A615,277(1997). 
H. Noumi, S. Sawada, T. Hasegawa, N. Horikawa, M. Ieiri, M. Ishii, S. Ishimoto, T. Iwata, Y. Katoh, M. Kawabata, Y.D. Kim, M.A. Kovash, M. Minakawa, Y. Mizuno, F. Nakayama, H. Ogami, A. Ogawa, T. Sasaki, T.-A. Shibata, Y. Suzuki, M. Takasaki, K. Tamura, J. Trice, and Y. Yamanoi, "Neutron Beam Line at the KEK 12-GeV PS", Nucl. Instr. Meth. A382,519(1997).

R.W. Stotzer, T. Burger, P.D. Barnes, B. Bassalleck, A. Berdoz, M. Burger, R.E. Chrien, C. Davis, G. E. Diebold, H. Enyo, H. Fischer, G.B. Franklin, J. Franz, L. Gan, D. Gill, T. Iijima, K. Imai, P. Koran, L. Lee, J. Lowe, R. Magahiz, A. Masaike, C. Meyer, R. McCrady, F. Merrill, J. M. Nelson, K. Okada, S. Page, P. Pile, B. Quinn, W. Ramsay, E. Roessle, A. Rusek, R. Sawafta, H. Schmitt, R.A. Schumacher, R.L. Stearns, I.R. Sukaton, R. Sutter, J.J. Szymanski, F.

Takeutchi, W.T.H. Van Oers, D. M. Wolfe, K. Yamamoto, M. Yosoi, V.J. Zeps and R. Zybert, "Search for the H-Dibaryon in ${ }^{3} \mathrm{He}\left(\mathrm{K}^{-}, \mathrm{K}^{+}\right) \mathrm{Hn}$ ", Phys. Rev. Lett. 78(1997)3646.

P.D. Barnes, G. Franklin, B. Quinn, R.A. Schumacher, V. Zeps, N. Hamann, W. Dutty, H. Fischer, J. Franz, E. Rossle, H. Schmitt, R. Todenhagen, R.v. Frankenberg, K. Kilian, W. Oelert, K. Rohrich, K. Sachs, T. Sefzick, M. Ziolkowski, R.A. Eisenstein, P.G. Harris, D.W. Hertzog, S.A. Hughes, P.E. Reimer, R.L. Tayloe, W. Eyrich, R. Geyer, M. Kirsch, R.A. Kraft, F. Stinzing, T. Johansson and S. Ohlsson, "Measurement of the pp -> ëë reactions at 1.726 and $1.771 \mathrm{GeV}$ ", Phys. Rev. C54(1996)2831.

P.D. Barnes, G. Diebold, G. Franklin, B. Quinn, R. Schumacher, J. Seydoux, V. Zeps, P. Birien, W. Dutty, H. Fischer, J. Franz, E. Rossle, H. Schledermann, H. Schmitt, R. Todenhagen, W. Breunlich, N. Nagele, R. Broders, R. von Frankenberg, K. Kilian, W. Oelert, K. Rohrich, K. Sachs, T. Sefzick, G. Sehl, M. Ziolkowski, R.A. Eisenstein, D. Hertzog, R. Tayloe, H. Dennert, W. Eyrich, R. Geyer, J. Hauffe, A. Hofmann,M. Kirsch, R.A. Kraft, F. Stinzing and N. Hamann, "Observables in high-statistics measurements of the reaction pp -> ëë", Phys. Rev.

C54(1996) 1877.

W. Xu et al., "The Transverse Asymmetry A(T') From Quasielastic Polarized He-3 (Polarized e, e') Process and the Neutron Magnetic Form-Factor.", Phys.Rev.Lett.85:2900-2904(2000).

M. Amarian et al., 'The Spin Structure of He-3 at low Q^2 and the Extended Gersimov-Drell-Hearn Sum Rule for the Neutron", in preparation.

W. Korsch, "The Generalized Gersimov-Drell-Hearn Sum of the Neutron at low Q Using a Polarized He-3 Target”', Czech. J. Phys. 50, 101-108(2000).

F. Xiong, "Precision Measurement of the Spin-Dependent Asymmetry in the Threshold Region of Polarized He-3(Polarized e, e')", in preparation.

"GEP/GMP Ratio by Polarization Transfer in Polarized e p->e p", Jefferson Lab Hall A Collaboration, Phys. Rev. Lett. 84, 1398(2000). 
"Measurement of Recoil Proton Polarizations in the Electrodisintegration of Deuterium by Polarized Electrons", D.H. Barkhuff, C.S. Armstrong, W. Bertozzi, J.P. Chen, D. Dale, G. Dodson, K.A. Dow, M.B. Epstein, M. Farkhondeh, J.M. Finn, S. Gilad, M.K. Jones, K. Joo, J.J. Kelly, S. Kowalski, D. Liu, R.W. Lourie, J.I. McIntyre, R. Madey, D.J. Margaziotis, P. Markowitz, C. Mertz, B.D. Milbrath, J. Mitchell, S. Mukhopadhyay, C.F. Perdrisat, V. Punjabi, L. Qin, P.M. Rutt, A.J.Sarty, D. Tieger, C. Tschalaer, W. Turchinetz, P.E. Ulmer, S. Van Verst, C. Vellidis, G. Warren, L.B. Weinstein, R.J. Woo, Phys. Lett. B470 39, (1999).

"Measurement of the neutral weak form factors of the proton", K.A. Aniol, D.S. Armstrong, M. Baylac, E. B Burtin, J. Calarco, G.D. Cates, C. Cavata, J.-P. Chen, E. Chudakov, D. Dale, C.W. de Jager, A. Deur, P. Djawotho, M.B. Epstein, S. Escoffier, L. Ewell, N. Falleto, J.M. Finn, K. Fissum, A. Fleck, B. Frois, J. Gao, F. Garibaldi, A. Gasparian, G.M. Gerstner, R. Gilman, A. Glamazdin, J. Gomez, V. Gorbenko, O. Hansen, F. Hersman, R. Holmes, M. Holtrop, B. Humensky, S. Incerti, J. Jardillier, M.K. Jones, J. Jorda, C. Jutier, W. Kahl, D.H. Kim, M.S. Kim, K. Kramer, K.S. Kumar, M. Kuss, J. LeRose, M. Leuschner, D. Lhuillier, N. Liyanage, R. Lourie, R. Madey, D.J. Margaziotis, F. Marie, J. Martino, P. Mastromarino, K. McCormick, J. McIntyre, Z.-E. Meziani, R. Michaels, G.W. Miller, D. Neyret, C. Perdrisat, G.G. Petratos, R. Pomatsalyuk, J.S. Price, D. Prout, V. Punjabi, T. Pussieux, G. Quemener, G. Rutledge, P.M. Rutt, A. Saha, P.A. Souder, M. Spradlin, R. Suleiman, J. Thompson, L. Todor, P.E. Ulmer, B. Vlahovic, K. Wijesooriya, R. Wilson, B.Wojtsekhowski, Phys. Rev. Lett. 82, no. 6, 1096, (1999).

W. Korsch, "The Generalized Gersimov-Drell-Hearn Sum of the Neutron at low Q Using a Polarized ${ }^{3} \mathrm{He}$ Target", International Conference SPIN99, Prague (Czech Republic), September 1999, invited plenary talk.

W. Korsch, "The Generalized Gerasimov-Drell-Hearn Sum of the Neutron at Low Q", International Conference DIS01, Bologna (Italy), May 2001, invited talk.

P. Zolnierczuk, "The Generalized Gerasimov-Drell-Hearn Sum of the Neutron", International Conference SPIN01, Moscow (Russia), August 2001, invited talk.

D. Dale, "A Moller Polarimeter for Hall A of TJNA", Invited talk at Polarized Targets and Beams, Seventh International Workshop, Urbana, IL, 1997. Invited talk.

Jeananne Miller (undergraduate student), oral presentation at the National Conference on Undergraduate Research 2001, University of Kentucky, March 2001, Title: "Measurement of the Longitudinal Spin Relaxation Time in Water". 


\section{IV.d. Research Cluster 4: Materials Research}

\section{Project 1: Synthesis and Applications of Sol-Gel Yittria Stabilized Zirconia}

PRINCIPAL INVESTIGATOR: Burtron H. Davis, Center for Applied Energy Research, University of Kentucky, 2540 Research Park Drive, Lexington, KY 40511, tel (859) 257-0251, fax (859) 257-0302 e-mail davis@caer.uky.edu.

\section{CO-PRINCIPAL INVESTIGATORS:}

Also at the University of Kentucky:

R. Srinivasan, Research Materials Scientist, Center for Applied Energy Research, tel (859) 2570234, fax (859) 257-0302, e-mail met130@ukcc.uky.edu.

D. Sparks, Research Engineer, Center for Applied Energy Research, tel: (859) 257-0257; fax (859) 257-0302; e-mail,sparks@,caer.uky.edu.

Robert Guthrie, Professor, Chemistry Department, tel: (859) 257-7068, fax (859) 323-1069, email rguthrie@pop.uky.edu

At other universities:

W.P. Pan, Chemistry Department, Western Kentucky University, Bowling Green, KY 42101 tel (502) 745-5322, fax (502) 745-6293, email Wei-Ping.Pan@wku.edu

D. Collins, Department of Chemical Engineering, University of Louisville, Louisville, KY 40292, tel (502) 852-6737, fax (502) 852-6355, email djcoll01@ulkyvm.louisville.edu

Pasha Ganesan, Inco Alloys International, 3200 Riverside Dr., Huntington, WV 25705 tel (304) 526-5762, fax: (304) 526-5973

Gaylord Smith, Inco Alloys International, 3200 Riverside Dr., Huntington, WV 25705 tel (304) 526-5735, fax (304) 526-5973

Richard Knight, Department of Materials Engineering, CPPM, Drexel University, Philadelphia, PA 19104, tel (215) 895-1990, fax (215) 895-2332, email knight@duvm.ocs.drexel.edu

\section{SUMMARY}

Beginning in October 1994, a number of small (20-50g) samples of yttria stabilized zirconia (YSZ) were produced using the sol-gel preparation technique. This series of samples ranged from $1-15$ mole percent (1.8-24.4 wt \%) yttria and were shown by scanning electron 
microscope (SEM) to consist of very fine ( $<10$ micron) agglomerations of mostly non-spherical particles.

Thermogravimetric analysis (TGA) was used to determine the temperature for the onset of crystallization of the zirconias, which as expected, increased with increasing yttria content. Xray diffraction analysis (XRD) indicated that samples containing at least 3 mole\% yttria demonstrated good stability in the tetragonal and/or cubic phases with prolonged exposure to $1000^{\circ} \mathrm{C}$.

In a continuation of the particle morphology study, small samples of zirconia were also produced by precipitation from an aqueous solution of zirconyl nitrate and by the hydrolysis of both zirconium n-propoxide and isopropoxide.

Critical point solvent extraction (CPSE) was tried in an attempt to reduce agglomeration. Sol-gel zirconia was produced and rinsed as before, but was re-slurried with methanol after the last rinse instead of drying it in an oven. The zirconia/methanol mixture was loaded into a high pressure autoclave and heated under nitrogen to $-240^{\circ} \mathrm{C}$, the critical temperature of methanol. With no methanol remaining in the liquid phase, the autogenic pressure was rapidly vented, producing a "fluffier" zirconia. BET surface area and DTA exotherm event temperature were both increased.

In a continuation of the particle morphology study, several additional 20-50g samples of YSZ were produced using zirconium n-propoxide as a precursor. A $1 \mathrm{~kg}$ sample of pure zirconia was precipitated from an aqueous zirconium chloride solution using excess ammonia. After repeated rinses to remove chlorine ions, the zirconia was then dried at $110^{\circ} \mathrm{C}$ and crushed. This amorphous material was then used in a series of experiments involving the doping of yttria onto the surface of zirconia.

A number of small samples of co-precipitated yttria/hafnias and yttria/zirconia/hafnias were produced and sintered at temperatures up to $1000^{\circ} \mathrm{C}$. XRD was used to determine the crystalline phase composition. TGA tests were performed on the as-produced powders to determine crystallization temperatures.

It was decided that the fine powder YSZ produced by precipitation from an aqueous zirconium chloride/yttrium nitrate solution would be the first candidate for thermal barrier coating (TBC) testing. A $2 \mathrm{~kg}$ batch of zirconia containing $8 \mathrm{wt} \%$ yttria was prepared at the CAER. It showed a clear superiority over the commercial product in its percentage of monoclinic phase present. Both YSZ's were sintered in air at $1000^{\circ} \mathrm{C}$ for over 200 hours and the amount of monoclinic phase in each remained unchanged. The XRD data showed no monoclinic phase, while the commercial YSZ showed 30\%. The XRD of the commercial YSZ after it had been plasma sprayed onto the test coupons subsequently revealed that the monoclinic content had dropped to $\sim 8 \%$. After plasma spraying, the CAER YSZ still contained no monoclinic structure.

Super alloys used in turbine or other heat engine components experience corrosive and/or erosive environments at high temperatures (above about $1000^{\circ} \mathrm{C}$ ). Because of high-temperature corrosion, the life of engine components and engine performance suffer. To insulate these super alloy engine components from severe high temperature corrosion, a thermal barrier coating (TBC) may be applied. Because of its low thermal conductivity, the coating insulates the underlying metallic material from the high gas temperatures. The desired properties for the thermal barrier coatings also include a relatively high thermal expansion coefficient to more 
closely match that of the metal, and stability during thermal cycling. The thermal shock resistance of the thermal barrier coatings is greatly influenced by the thermal expansion coefficient $(\alpha)$ mismatch between the top coat and the metallic substrate.

The thermal conductivity of $\mathrm{ZrO}_{2}$ is low, $0.05 \mathrm{cal}^{\circ} \mathrm{C}^{-1} \mathrm{sec}^{-1}$, compared with $0.5 \mathrm{cal}{ }^{\circ} \mathrm{C}^{-1}$ $\mathrm{sec}^{-1}$ for many metals. This order of magnitude difference in thermal conductivities allows thin layers to act as effective thermal barriers. For example, plasma-sprayed $\mathrm{ZrO}_{2}$ coating with an applied thickness of a ceramic coating of only 127 microns reduced the temperature of a metal surface operated at $1055^{\circ} \mathrm{C}$ by about $190^{\circ} \mathrm{C}$.

However, pure zirconia undergoes a volume change as it transforms from the tetragonal phase to the monoclinic phase upon cooling to room temperature, limiting its usefulness as an applied thermal barrier coating. The addition of various amounts of yttria is widely used to help stabilize the zirconia in the tetragonal or cubic phase, eliminating or reducing the volume change, making yttria stabilized zirconia a suitable material for thermal barrier coatings.

Hafnia has lower thermal conductivity than zirconia and this makes it even more attractive as a thermal barrier coating material. Another advantage is that the tetragonal to monoclinic transformation temperature is much higher for hafnia than for zirconia (1700 versus $1000^{\circ} \mathrm{C}$ ). However, hafnia exhibits a lower volume expansion than zirconia during the transformation, and this lower shear strain associated with the transformation could decrease the toughness of the hafnia based coating. Likewise, it appears more difficult to stabilize hafnia in the tetragonal form.

A potential application of the mixed $\mathrm{Hf} / \mathrm{Zr}$ oxides is the fact that the $\mathrm{t}-\mathrm{m}$ transformation temperature increases almost linearly with increasing $\mathrm{Hf}$ content in the mixed oxide solid solution. Unfortunately, the literature contains sparse data on the stability of the solid solutions at high temperatures and the dependence upon stabilizers, such as $\mathrm{Y}, \mathrm{Mg}$ and $\mathrm{Ca}$ oxides as well as the size of the grain size of hafnia in various materials.

Sample synthesis was carried out at the University of Kentucky's Center for Applied Energy Research. They were then applied to metallic test coupons using the plasma spray technique by The Center for Plasma Processing of Materials at Drexel University or by the Thermal Spray Laboratory at the State University of New York at Stony Brook. Additional characterization studies were conducted using facilities at Inco Alloys International, Inc. in Huntington, WV; Oak Ridge National Laboratories and Argonne National Laboratory. Testing of coated coupons continued during the last year of this project, characterizing the coating's resistance to mechanical erosion and resistance to spalling due to asymmetric heating.

\section{FUNDING}

DOE: $\$ 409,301$

Commonwealth of Kentucky: $\$ 362,225$

Total: $\$ 771,526$

\section{ACCOMPLISHMENTS}


1. Ms. Coleman, an underrepresented graduate student in chemical engineering, University of Louisville, completed her Masters within the project research.

2. Ms. Bi completed Masters in Chemistry at Western Kentucky University within the project research. She subsequently began a Ph.D. degree in the Chemistry Department at the University of Florida, and has been awarded a doctorate.

3. Research interactions were initiated with Sandia National Laboratory where Ms. Coleman worked under the direction of Nancy Jackson.

4. Research interactions were initiated with the Pittsburgh Energy Technology Center where T. Fields worked under the direction of Bradley Bockrath.

5. R\&D contracts and awards outside of EPSCoR funding that totaled $\$ 8,855,279$ over the period of 1994-2002. This funding included the following:

Catalyst Testing, Conoco, 1998-2002 (\$850,000)

Thermal Barrier Coatings, USDOE, 1998-2001 $(\$ 104,000)$

History of Catalysis, The Catalysis Society, $1998(\$ 4,000)$

Heterogeneous Catalysis, unrestricted award - United Catalysts, Inc., $1998(\$ 10,000)$

Catalyst Testing, Chevron, $1998(\$ 75,000)$

Catalyst Testing, Howe-Baker $1998(\$ 100,000)$

Catalyst Testing, Reema, $1998(\$ 25,000)$

Technology Development for Iron and Cobalt Fischer-Tropsch Catalysts, USDOE, 1998$2001(\$ 3,910,000)$

Thermal Barrier Coating, USDOE, 1997-2001 (\$134,000)

Catalyst Activity Testing, Energy International, $1997(\$ 12,500)$

Heterogeneous Catalysis, United Catalysts, $1997(\$ 10,000)$

Conversion of $\mathrm{H}_{2} \mathrm{~S}$ to Sulfur, Parons/United Catalysts, Inc., $1996(\$ 20,000)$

Heterogeneous Catalysis, United Catalysts, Inc., $1996(\$ 10,000)$

Zirconia Thermal Barrier Coating, USDOE, 1995-1997 (\$139,806)

Heterogeneous Catalysis, United Catalysts, Inc., $1995(\$ 10,000)$

Acetylene Hydrogenation, United Catalysts, Inc., $1995(\$ 62,000)$

Technology Development for Iron Fischer-Tropsch Catalysts,USDOE, 1994-1997

$(\$ 3,246,473)$

Heterogeneous Catalysis, United Catalysts, Inc., $1994(\$ 10,000)$

Acetylene Hydrogenation, United Catalysts, Inc., $1994(\$ 5,000)$

Symposium support, honoring Robert Eischens, ACS Petroleum Fund, 1994 (\$5,000)

\section{PUBLICATIONS AND PRESENTATIONS}

R. Srinivasan, D. E. Sparks, D. R. Milburn and B. H. Davis, Synthesis and structural studies of microporous yttria-stabilized zirconia ceramics, "Microporous and Macroporous Materials," (R. L. Lobo, et al., eds), Materials Res. Soc., Symp. Proc., 431, 279-284 (1996).

B.H. Davis, R. A. Keogh and R. Srinivasan, $\mathrm{Pt}-\mathrm{SO}_{4}{ }^{2-}-\mathrm{ZrO}_{2}$ Catalysts: The impact of water on their activity for hydrocarbon conversion, J. Catal., 151, 292 (1995). 
B.H. Davis, R. Srinivasan, R. A. Keogh and D. R. Milburn, Sulfated zirconia catalysts: Characterization by TGA/DTA/Mass spectrometry, J. Catal., 153, 123 (1995).

M. Bi, H. Li, W.-P. Pan, W. G. Lloyd and B. H. Davis, Thermal studies of metal promoted sulfated zirconia, Div. Fuel Chem. Preprints, 41, 77 (1996).

B.H. Davis, R. Srinivasan, T. R. Watkins and C. R. Hubbard, Sulfated zirconia catalysts. The crystal phases and their transformation, Chem. Mater., 7, 725 (1995).

B.H. Davis, Srinivasan and R. Keogh, Activation and characterization of Fe-Mn- $\mathrm{SO}_{4}{ }_{4}^{2-} / \mathrm{ZrO}_{2}$ catalysts, Appl. Catal., A: General, 130, 135 (1995).

D. R. Milburn, B. D. Adkins, D. E. Sparks, R. Srinivasan and B. H. Davis, Applications of supercritical drying in catalyst preparation, Advanced Catalysts and Nanostructured Materials, Academic Press Inc., New York, 1996, pp 117-142.

M. Bi, H. Li, W.-P. Pan, W. G. Lloyd and B. H. Davis, Thermal Studies of $\left(\mathrm{NH}_{4}\right)_{2} \mathrm{Cr}_{2} \mathrm{O}_{7},\left(\mathrm{NH}_{4} \mathrm{O}_{2}\right.$ $\mathrm{WO}_{4}$, and $\left(\mathrm{NH}_{4}\right)_{6} \mathrm{Mo}_{7} \mathrm{O}_{24} \bullet 4 \mathrm{H}_{2} \mathrm{O}$ deposited on $\mathrm{ZrO}_{2}{ }^{1}$, Thermochimica Acta, 482, 153 (1996).

R. Keogh, R. Srinivasan and B. Davis, "Catalytic Properties of Sulfated Zirconia Superacid Catalysts," 7th Japan-China-USA Symposium on Catalysis, Tokyo, Japan, July 24-28, 1995.

R. Keogh, R. Srinivasan and B. Davis. Catalytic Properties of Sulfated Zirconia Superacid Catalysts, Tri-State Catalyst Club Spring Symposium, Charleston, WV, April, 1995.

R. Srinivasan, R. A. Keogh and B. H. Davis, Characterization of various sulfated zirconia superacid catalysts by simultaneous TG/MS technique, Pittsburgh Catalysis Society Spring Symposium, May 9-12, 1995, Pittsburgh, PA.

R. Srinivasan, R. A. Keogh and B. H. Davis, Characterization of various sulfated zirconia superacid catalysts by simultaneous TG/MS technique, 14th North American Meeting of The Catalysis Society, June 11-16, 1995, Snowbird, Utah.

A. M. Brenner, B. H. Davis and J. T. Schrodt, Cracking of 2-methylbutane and Carbon-14 labelled 2-methylbutane over a silica-alumina catalyst, 14th North American Meeting of The Catalysis Society, June 11-16, 1995, Snowbird, Utah.

R. Keogh, R. Srinivasan and B. Davis, "Sulfated Zirconia as a Solid Superacid Catalyst," 1995 Intl. Chemical Congress of Pacific Basin Societies, December 17-22, 1995, Honolulu, Hawaii.

B.H. Davis and D.R. Milburn, Comparison of t-plots for carbons, silicas and aluminas, Proc. 4 th IUPAC Symp. on Characterization of Porous Solids, University of Bath, September 15-18, 1996 pp 275-282. 
R. Srinivasan, R. A. Keogh and B. H. Davis, Sulfated zirconia catalysts: Are Brønsted acid sites the source of activity?, Catal. Lett., $\underline{36}, 51$ (1996).

R. Srinivasan, R. A. Keogh, A. Ghenciu, D. Farcasiu and B. H. Davis, Reaction of benzene and pyridine on metal-promoted sulfated zirconia catalysts, J. Catal., 158, 502 (1996).

R. A. Keogh, R. Srinivasan and B. H. Davis, The effect of Pt concentration on the activity and selectivity of $\mathrm{SO}_{4}{ }^{2-}-\mathrm{ZrO}_{2}$ catalysts for the hydrocracking and hydroisomerization of $\mathrm{n}$ hexadecane. Applied Catal. A; General, 140, 47-57 (1996).

R. Srinivasan, D. E. Sparks and B. H. Davis, State of platinum in zirconia and sulfated zirconia catalysts, Catal. Lett., $\underline{40}, 167$ (1996).

D. E. Sparks, R. A. Keogh and B. H. Davis, Platinum-sulfated zirconia catalysts. Dependence of activity on sulfur addition method, Appl. Catal. A: General, 144, 205 (1996).

D. R. Milburn, R. A. Keogh and B. H. Davis, $\mathrm{Pt}_{-} \mathrm{SO}_{4}{ }^{2-}-\mathrm{ZrO}_{2}$ catalysts. Correlation of catalytic activity with $\mathrm{SO}_{4}{ }^{2-}$ XPS Data, Appl. Catal. A: General, 147, 109 (1996).

B.H. Davis and R. Srinivasan, Zirconia: A review of super ceramic, in "Materials Synthesis and Characterization," (D. L. Perry, ed.), Plenum Press, New York, pp 147-188, 1997.

B.H. Davis, M. L. Occelli, S. Biz and R. A. Keogh, Effects of Cu and Ag on Sulfated Zirconia Catalysts, ACS Div. Petrol. Chem. Preprints, $\underline{42}, 741$ (1997).

B.H. Davis, An Investigation into the Activation of Solid Acid Catalysts, ACS Div. Petrol. Chem. Preprints, 42, 754 (1997).

B.H. Davis, The Regeneration of Pt Promoted $\mathrm{SO}_{4}{ }^{2-}-\mathrm{ZrO}_{2}$ Catalysts, ACS Div. Petrol. Chem. Preprints, $\underline{42}, 766$ (1997).

B.H. Davis, Development of the science of catalysis, "Handbook of Heterogeneous Catalysis," (G. Ertl, H. Knözinger and J. Weitkamp, eds.), John Wiley-VCH, New York, NY, 1997, pp 1335.

B.H. Davis, The swamping catalyst effect, Appl. Catal. A: General, 161, N3 (1997).

B.H. Davis, D. R. Milburn, R. A. Keogh and D. E. Sparks, XPS investigation of an iron/manganese/sulfated zirconia catalyst, Appl. Surf. Sci., 126, 11 (1998).

B.H. Davis, A. M. Brenner, J. T. Schrodt and B. Shi, Hydrogen production in the conversion of 2-methylbutane over a series of acid catalysts, Catal. Today, 44, 235 (1998). 
B.H. Davis, M. Bi, W-P. Pan and W. G. Lloyd, Platinum sulfated zirconia catalysts. Fate of chlorine during activation, Catal. Lett., $\underline{50}, 187$ (1998).

2. Project 2: Optimization of Heat Treatment of Aluminum-Silicon-Magnesium Alloys

Principal Investigator: Dr. Murat Tiryakioglu, Applied Technology Transfer Center, Western Kentucky University, Bowling Green, Kentucky

Dr. Wei-Ping Pan, Chemistry Department, Western Kentucky University, Bowling Green, KY 42101, tel (502) 745-5322, fax (502) 745-6293, email Wei-Ping.Pan@wku.edu

\section{SUMMARY}

This study looked at experimental models to optimize the heat treatment of aluminumsilicon-magnesium alloy castings. Quenching was to be optimized for controlling distortion and residual stresses while still retaining a majority of the solutes within the solid solution. Residual stress generation were to be linked to cooling conditions within castings, so that it would be possible to predict distortion and residual stresses based on quenching process parameters. Castings were then to be aged immediately after quenching, without having to be straightened. The results of this improvement are expected to be reduced furnace time during artificial aging, and the elimination of the need for keeping castings in freezers.

Once quenching conditions that yield minimal distortion were identified, solution treatment and aging studies were to be initiated. Optimal solution treatment times for a given temperature were to be examined along with sample microstructure. Precipitation of the strengthening phase $\left(\mathrm{Mg}_{2} \mathrm{Si}\right)$ in optimally quenched samples were to be studied, and the effects of several process variables on strength development during artificial aging investigated.

A Heat Treatment Laboratory was to be established at Western Kentucky University, and used jointly by the faculty, staff, and both graduate and undergraduate students of the Departments of Chemistry and Industrial Technology during this study.

\section{FUNDING}

DOE: $\quad \$ 32,625$

Commonwealth of Kentucky: $\$ 9,339$

Total: $\quad \$ 41,964$

\section{ACCOMPLISHMENTS}

This project began in 1999 and was part of an effort by the KY DOE EPSCoR Program to provide seed funding to some peer reviewed research such that a competitive position may have been established for innovative and sustaining research to be included in the Kentucky response to a DOE EPSCoR solicitation for Implementation Grants DOE in 2000. For this project, eEquipment and supplies for establishing the Heat Treatment Laboratory were ordered and had 
been delivered. However, after approximately six months into the project, the principal investigator left Western Kentucky University. No further research or progress was attempted.

\section{Project 3: Development of MEMS for DOE Applications}

Principal Investigators: Dr. Kevin M. Walsh and Dr. John F. Naber, Department of Electrical Engineering, University of Louisville, Louisville, KY

\section{SUMMARY}

This project began in 1999 and was part of an effort by the KY DOE EPSCoR Program to provide seed funding to some peer reviewed research such that a competitive position may be established for innovative and sustaining research to be included in the Kentucky response to a DOE EPSCoR solicitation for Implementation Grants in 2000.

The immediate goal of this proposal was to link the expertise at the University of Louisville in the area of Microelectromechanical Systems (MEMS) with the Department of Energy's (DOE) MEMS underway at Sandia National Laboratory in Albuquerque, New Mexico.

Integration was to be accomplished by having key MEMS personnel at the University of Louisville interface directly with Sandia's Intelligent Micromachine Department by participating

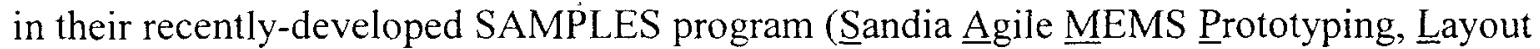
Tools, Education and Services program). This plan would be mutually-beneficial, with jointlydefined research into the design and fabrication of critical MEMS-based devices for specific DOE applications in the area of surface-micromachined micro-sensors, micro-actuators, and intelligent microsystems.

The project had a basis in the economic impact of MEMS-based devices as defined by Systems Planning Corporation. It estimated the market for MEMS-based devices and systems to be around $\$ 100$ Billion/year. Sandia National Laboratories was a recognized leader in this emerging field. The project promoted the development of close ties between UofL and Sandia. The long-term goal of the project was the sustainment of ongoing DOE MEMS research at UofL and in the state of Kentucky, and the emergence of a self-supporting MEMS Center at UofL which would serve the needs of all academic and industrial entities in the state of Kentucky and the nation.

FUNDING:

DOE: $\$ 32,611$

Commonwealth of Kentucky: $\$ 7,540$

Total: $\$ 40,151$

\section{ACCOMPLISHMENTS}

The research initiated within this seed funding enabled the investigators to successfully compete for Kentucky DOE EPSCoR funding within the 2000 DOE EPSCoR solicitation. At the 
time of this report, the project continues with significant support from other federal agencies and programs, and from industry.

\section{Project 4: Enhancement of Low-Field Magnetostriction In Thin, Multilayer Films for Device and Sensor Applications}

PRINCIPAL INVESTIGATOR: Dr. Craig A. Grimes, Dept. of Electrical Engineering, The University of Kentucky, Lexington, KY 40506

\section{CO-PRINCIPAL INVESTIGATORS:}

Dr. Elizabeth C. Dickey, Dept. of Chemical and Materials Engineering, University of Kentucky, Lexington, KY 40506

Dr. Rony Shahidain, Division of Mathematics and Sciences, Kentucky State University, Frankfort, KY

\section{SUMMARY}

This project began in 1999 and was part of an effort by the KY DOE EPSCoR Program to provide seed funding to some peer reviewed research such that a competitive position may be established for innovative and sustaining research to be included in the Kentucky response to a DOE EPSCoR solicitation for Implementation Grants in 2000.

Micromechanical devices offer the promise of a technological revolution comparable to that of photolithographically defined silicon. Associated with these microsystem devices is an interest in thin film materials that possess very high values of low-field magnetostriction; such materials would be ideally suited for fabrication of miniature or microscale thin film actuators, pumps, sensors, or dosimeters. The potential economic and social benefits of such microdevices is vast. Therefore, this project sought to initiate a multi-discipline research effort to: (1) develop new, low-field highly magnetostrictive thin films; (2) develop a frequency dependent theoretical model of magnetostriction to guide alloy development for device specific needs; (3) develop a new, permeameter-like device capable of measuring the high-frequency magnetostriction of thin films; and (4) fabricate new low-field magnetostriction based devices such as actuators, and temperature, viscosity, and chemical sensors.

The proposal also included a educational outreach component to Kentucky State University and, through this outreace, to interest a diverse cultural mix of students in magnetism and sensor related research. The aim was to provide education and graduate training to students in an exciting, new area who subsequently would support Kentucky's and the nation's growing magnet, transformer, and sensor related industries.

\section{FUNDING}

DOE: $\$ 38,497$

Commonwealth of Kentucky: $\$ 0$ 
Total: $\$ 38,497$

\section{ACCOMPLISHMENTS}

The research initiated within this seed funding enabled the investigators to successfully compete for Kentucky DOE EPSCoR funding within the 2000 DOE EPSCoR solicitation. At the time of this report, however, the two key researchers in the project - Dr. Grimes and Dr. Dickey have left Kentucky and have begun employment at the University of Pennsylvania. Nevertheless, their research continues with significant support from federal agencies and programs, and from industry. 